Atmos. Chem. Phys., 13, 8973-8989, 2013

www.atmos-chem-phys.net/13/8973/2013/

doi:10.5194/acp-13-8973-2013

(c) Author(s) 2013. CC Attribution 3.0 License.

\title{
Measuring and modeling the hygroscopic growth of two humic substances in mixed aerosol particles of atmospheric relevance
}

\author{
I. R. Zamora ${ }^{1}$ and M. Z. Jacobson ${ }^{2}$ \\ ${ }^{1}$ Department of Geophysics, Stanford University Yang and Yamazaki Environment and Energy Building, 473 Via Ortega, \\ Room M05, Stanford, California 94305, USA \\ ${ }^{2}$ Department of Civil and Environmental Engineering, Stanford University Yang and Yamazaki Environment and Energy \\ Building, 473 Via Ortega, Room 397, Stanford, California 94305, USA
}

Correspondence to: I. R. Zamora (luziro@alumni.stanford.edu) and M. Z. Jacobson (jacobson@stanford.edu)

Received: 20 December 2012 - Published in Atmos. Chem. Phys. Discuss.: 9 January 2013

Revised: 10 July 2013 - Accepted: 18 July 2013 - Published: 9 September 2013

\begin{abstract}
The hygroscopic growth of atmospheric particles affects atmospheric chemistry and Earth's climate. Watersoluble organic carbon (WSOC) constitutes a significant fraction of the dry submicron mass of atmospheric aerosols, thus affecting their water uptake properties. Although the WSOC fraction is comprised of many compounds, a set of model substances can be used to describe its behavior. For this study, mixtures of Nordic aquatic fulvic acid reference (NAFA) and Fluka humic acid (HA), with various combinations of inorganic salts (sodium chloride and ammonium sulfate) and other representative organic compounds (levoglucosan and succinic acid), were studied. We measured the equilibrium water vapor pressure over bulk solutions of these mixtures as a function of temperature and solute concentration. New water activity $\left(a_{\mathrm{w}}\right)$ parameterizations and hygroscopic growth curves at $25^{\circ} \mathrm{C}$ were calculated from these data for particles of equivalent composition. We examined the effect of temperature on the water activity and found a maximum variation of $9 \%$ in the $0-30^{\circ} \mathrm{C}$ range, and $2 \%$ in the $20-30{ }^{\circ} \mathrm{C}$ range. Five two-component mixtures were studied to understand the effect of adding a humic substance (HS), such as NAFA and HA, to an inorganic salt or a saccharide. The deliquescence point at $25^{\circ} \mathrm{C}$ for HSinorganic mixtures did not change significantly from that of the pure inorganic species. However, the hygroscopic growth of HA/ inorganic mixtures was lower than that exhibited by the pure salt, in proportion to the added mass of HA. The addition of NAFA to a highly soluble solute (ammonium sulfate, sodium chloride or levoglucosan) in water had the same effect as the addition of HA to the inorganic species for most
\end{abstract}

of the water activity range studied. Yet, the water uptake of these NAFA mixtures transitioned to match the growth of the pure salt or saccharide at high $a_{\mathrm{w}}$ values. The remaining four mixtures were based on chemical composition data for different aerosol types. As expected, the two solutions representing organic aerosols ( $40 \%$ HS / $40 \%$ succinic acid / $20 \%$ levoglucosan) showed lower water uptake than the two solutions representing biomass burning aerosols ( $25 \% \mathrm{HS} / 27 \%$ succinic acid $/ 18 \%$ levoglucosan $/ 30 \%$ ammonium sulfate). However, interactions in multicomponent solutions may be responsible for the large variation of the relative water uptake of identical mixtures containing different HSs above a water activity of 0.95 . The ZSR (Zdanovskii, Stokes, and Robinson) model was able to predict reasonably well the hygroscopic growth of all the mixtures below $a_{\mathrm{w}}=0.95$, but produced large deviations for some multicomponent mixtures at higher values.

\section{Introduction}

The hygroscopic growth of atmospheric aerosols impacts public health, atmospheric chemistry, and Earth's climate. The uptake of water by aerosol particles influences their health effects, as reported in epidemiological studies (e.g., Pöschl, 2005, and references therein). It also alters aerosol chemical reactivity, aging and its effects on visibility and atmospheric composition (Sloane and Wolff, 1985; Pandis et al., 1995). Moreover, the interaction between water vapor and aerosol particles is central to the climate effects of 


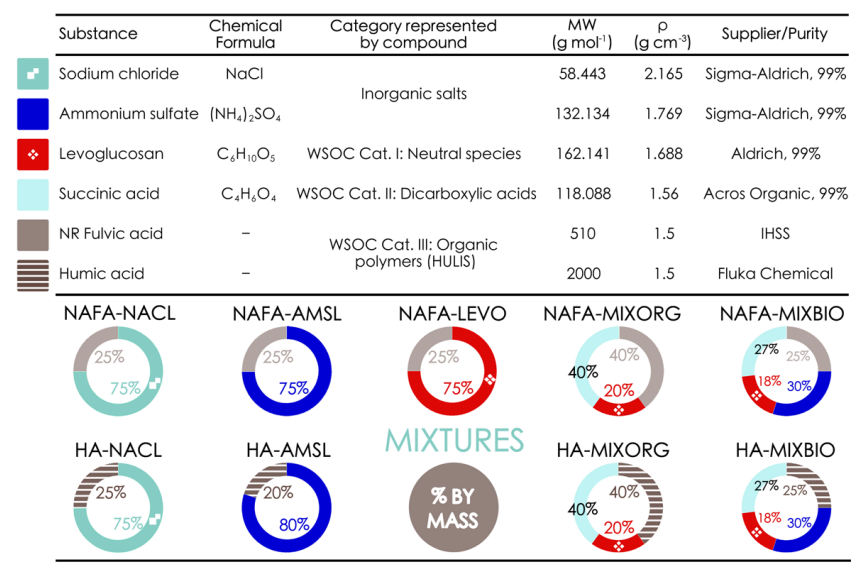

Fig. 1. Substances chosen as model compounds, their properties and mixtures of these substances studied in this work.

atmospheric aerosols - both their direct effect by radiation scattering and their indirect effects by modifying cloud properties. These climate effects account for the largest cause of uncertainty in radiative forcing estimates (IPCC, 2007).

Atmospheric particles consist of a mixture of organic and inorganic components. The inorganic portion, previously thought to dominate the water uptake of atmospheric aerosols, has been well characterized. Organic matter can be $20-50 \%$ of the total fine aerosol mass (Saxena and Hildemann, 1996; Putaud et al., 2004), and as high as $90 \%$ over biomass burning regions during burning season (Andreae and Crutzen, 1997; Talbot et al., 1988, 1990; Artaxo et al., 1988, 1990; Roberts et al., 2001; Bond et al., 2004). Between 45 and $75 \%$ of this organic matter is watersoluble organic carbon (WSOC) and may therefore influence the hygroscopic growth behavior of atmospheric aerosols (Decesari et al., 2005; Saxena and Hildemann, 1996; Mader et al., 2004). This influence has been the subject of ongoing research during the past decade, though our knowledge is still limited (Kanakidou et al., 2005; Zhang et al., 2007; Hallquist et al., 2009).

Challenges in studying the hygroscopic behavior of the organic fraction are its complexity and the lack of information about its chemical composition (Jimenez et al., 2009). Fuzzi et al. (2001) proposed identifying a set of model compounds that can reproduce the behavior of the WSOC fraction of real aerosol particles with the help of chromatographic separation and proton nuclear magnetic resonance (HNMR) analysis. This analysis of WSOC from aerosol filter samples shows that it contains compounds in three categories: (i) neutral species, such as saccharides; (ii) mono/dicarboxylic acids; and (iii) water-soluble surfactants, including humic-like organic polymers (Fuzzi et al., 2001; Mayol-Bracero et al., 2002; Decesari et al., 2005). Decesari et al. (2001) identified up to $40 \%$ of WSOC as polycarboxylic acids resembling the molecular structures of humic materials using the same HNMR technique. The similarity of the polycarboxylic acid fraction to humic materials, observed in several studies (Mukai and Ambe, 1986; Havers et al., 1998; Facchini et al., 1999; Gelencsér et al., 2000; Krivácsy et al., 2000; Duarte et al., 2005; Alfarra et al., 2006), has earned this fraction the name HUmic-LIke Substances (HULIS).

Following this approach, we have chosen model compounds to represent each WSOC category in order to study the water uptake of mixed atmospheric particles. Levoglucosan, a saccharide that is used as a tracer for biomass burning (Simoneit et al., 1999), was selected to represent category I. Succinic acid, often identified as one of the most abundant dicarboxylic acids in atmospheric aerosol samples (Rogge et al., 1993; Chebbi and Carlier, 1996; Kerminen et al., 2000; Kawamura et al., 2001a, b; Narukawa et al., 2002, Jung et al., 2010; Hegde and Kawamura, 2012), was chosen to represent category II. The humic substances Nordic aquatic fulvic acid reference (NAFA) and Fluka humic acid (HA), obtained from the International Humic Substance Society (IHSS), were chosen as model compounds for category III. To represent the inorganic component that can contribute to water uptake, we use sodium chloride and ammonium sulfate, two inorganic salts ubiquitous in the atmosphere. Figure 1 lists these substances, along with their properties, and the nine different mixtures prepared for this work. Two-component mixtures were made in order to study the mixed particles of humic substances with inorganic salts (NAFA-NACL, NAFA-AMSL, HA-NACL, and HA-AMSL), and with a category I compound (NAFA-LEVO). The composition of the remaining mixtures (NAFA-MIXORG, HA-MIXORG, NAFA-MIXBIO, and HA-MIXBIO) was adopted from two mixtures studied by Svenningsson et al. (2006) with the hygroscopic tandem differential mobility analyzer (HTDMA). MIXORG and MIXBIO contained a different fulvic acid, Suwannee River fulvic acid (SRFA), and were based on chemical analyses of different aerosol types. MIXORG represents the organic portion of continental polluted aerosol, and MIXBIO represents biomass burning aerosols (Zappoli et al., 1999; Decesari et al., 2001; Artaxo et al., 2002; MayolBracero et al., 2002).

Numerous laboratory studies on hygroscopic growth of mixed aerosol particles have been published in the last years. Many have explored the effect of dicarboxylic acids on the deliquescence and water uptake of inorganic salts using the HTDMA (Cruz and Pandis, 2000; Hämeri et al. 2002; Moore and Raymond, 2008; Prenni et al., 2003; Sjogren et al., 2007; Wu et al., 2011), electrodynamic balance (EDB) (Lightstone et al., 2000; Choi and Chan, 2002a; Sjogren et al., 2007), and bulk (Brooks et al., 2002; Wise et al., 2003; Marcolli et al., 2004) methods. Fewer studies have examined the hygroscopic behavior of mixtures containing humic substances and inorganic salts, and all but one have done so with particle methods such as the EDB (Chan and Chan, 2003; Sjogren et al., 2007) and the HTDMA (Badger et al., 2006; Brooks et al., 2004; Svenningsson et al., 2006; Sjogren et al., 2007). 
The hygroscopic growth of NAFA has been studied in pure particles with a HTDMA (Gysel et al., 2004), and in a $50: 50$ mass ratio mixture with ammonium sulfate with an osmometer (Frosch et al., 2011). However, ours appears to be the only study to date to focus on NAFA in multicomponent mixtures and to study the water uptake of humic and fulvic acid mixtures with a bulk solution method.

Bulk water activity measurements present a method to corroborate the hygroscopic growth data measured directly with the HTDMA or EDB due to the simplicity of the equipment setup and the measurement procedure. Our bulk method eliminates the problems of fully drying particles, the effects of the equipment setup and of the measurement procedure. While the dehydration branch of the hygroscopic growth curve cannot be examined, bulk measurements can be collected at higher water activity values than HTDMA or EDB measurements. Another advantage is that water activity can be directly measured and parameterized in terms of solution concentration. A recent review article on the role of organic aerosols in global climate modeling identified a critical need for parameterizations of water activity from available data and future studies (Kanakidou et al., 2005). One simple way to model the water uptake of mixed particles is the Zdanovskii, Stokes, and Robinson (ZSR) method (Stokes and Robinson, 1966). The ZSR method predicts mixed particle hygroscopic growth by calculating the particle water content as the sum of the water content associated with the pure components comprising that particle at a specific relative humidity (RH). It is based on the assumption that individual components do not interact. Several studies on hygroscopic growth of mixed particles have compared their results with the ZSR method (Alshawa et al, 2009; Brooks et al., 2004; Choi and Chan, 2002a, b; Cruz and Pandis, 2000; Meyer et al., 2009; Moore et al., 2008; Prenni et al., 2003; Svenningsson et al., 2006; Sjogren et al., 2007; Wise et al., 2003; Wu et al., 2011). We have chosen to test the strength of this widely used method to predict the hygroscopic growth of our mixtures.

In this work, we study the hygroscopic growth of aerosol particles containing two humic substances, each mixed with organic and inorganic components. Model compounds based on the approach proposed by Fuzzi et al. (2001) were chosen to represent the organic component. Two inorganic salts of atmospheric relevance were chosen to represent the inorganic component. The mixtures studied, along with their chemical composition, are shown in Fig. 1. The hygroscopic growth of the particles was calculated from bulk water vapor pressure measurements over solutions of equivalent composition. The equilibrium water vapor pressure was measured as a function of temperature and solution concentration with a water activity apparatus. This study builds upon our previous work quantifying the hygroscopic growth of single organic solutes (Zamora et al., 2011).

This work aims to (1) generate water activity parameterizations for pure substances and mixtures at $25^{\circ} \mathrm{C}$ in the form of concentration vs. water activity; (2) quantify the effect of humic substances on the hygroscopic growth of inorganic salts and of a saccharide; (3) compare the hygroscopic behavior of two humic substances, of different molecular weight ranges, in the mixtures of atmospheric relevance; (4) explore the effect of temperature on the water activity of mixtures in the $0-30{ }^{\circ} \mathrm{C}$ range; and (5) assess the ability of the ZSR method to estimate the hygroscopic growth of the mixtures studied.

\section{Material and methods}

\subsection{Materials and solution preparation}

Solutions were prepared by weighing each solid component and water into a glass vessel, then stirring until the solution became as homogeneous as possible. It is worth noting that some suspended solid was visible on the solutions at higher concentrations, indicating that not all of the solid went into the solution. Figure 1 lists all chemicals used in the solutions along with their manufacturer, purity, and relevant properties. All chemicals were used without further purification. Water employed in the preparation of solutions was filtered through a Millipore Synergy 185 system (EMD Millipore, Billerica, MA), with a resulting resistivity of $18.2 \mathrm{~m} \Omega$. For mixed solutions containing NAFA, multiple dilutions prepared from a concentrated stock solution were used due to the limited quantities available of IHSS standards (IHSS, 2012, https://ihss.humicsubstances.org/).

\subsection{Measuring water vapor pressure}

Water vapor pressure measurements were conducted with a bulk method described in detail by Zamora et al. (2011). Briefly, the apparatus used consists of a removable glass sample vessel, mechanically pumped glass lines wrapped with heating tape, a temperature-controlled bath, and a 100 torr Baratron capacitance manometer (Model 626A12TBE, MKS Instruments, Andover, MA). Approximately $3 \mathrm{~g}$ of the solution of interest were transferred to the sample vessel, which contained a Teflon-coated magnetic stirring bar to ensure a homogenous composition for the solution. After the sample vessel was connected to the apparatus, several freeze-purgethaw cycles were performed to evacuate the gas headspace above the solution.

The sample vessel was then submerged in a constant temperature bath at the desired temperature. The temperature was monitored by a thermocouple (Digi-sense RTD Platinum Thermometer, Eutech Instruments, Vernon Hills, IL) attached to the outside of the vessel, with an accuracy of $\pm 0.03{ }^{\circ} \mathrm{C}$. The system was considered to be at equilibrium when the temperature had been maintained within $\pm 0.1{ }^{\circ} \mathrm{C}$ of the target for at least $30 \mathrm{~min}$. After recording the vapor pressure reading from the barometer, the solution was frozen and any remaining pressure reading was subtracted from the measurement to prevent its distortion by a potential air leak. 
Air leaks were infrequent and never exceeded 0.2 torr. To avoid directional bias, each data point reported in the water activity vs. temperature curves was averaged over duplicate measurements taken in both the increasing and decreasing temperature directions.

\subsection{Quality assurance}

For each temperature, a water vapor pressure measurement was calibrated by subtracting the difference between our value and that obtained from the Aerosol Inorganic Model (AIM) (Clegg et al., 1998) for pure water. Our method was validated with sodium chloride and ammonium sulfate. Water vapor pressure measurements over aqueous solutions of these inorganic salts at $25.0^{\circ} \mathrm{C}$ matched the values predicted by AIM. The deliquescence relative humidity (DRH) and hygroscopic growth factor values calculated from these data were in good agreement with values from published TDMA, EDB and bulk studies. The uncertainty associated with the water activity at $25^{\circ} \mathrm{C}$ of pure solutes was reported to be between 0.007 and 0.018 in our previous work. This uncertainty range was found over a relative humidity range of 70-99.9\%. Full details of our method calibration, validation and quality control experiments can be found in Zamora et al., 2011.

This study employed a thermocouple with higher accuracy; thus the measurement uncertainty for the mixtures is lower than for the pure substances. This uncertainty was based on the accuracy of the thermocouple, and on the precision obtained experimentally for the vapor pressure measurements. The uncertainty range for the water vapor pressure measurements collected in the $0-30^{\circ} \mathrm{C}$ range was found to be $0.3-1.4 \%$, with the highest uncertainty occurring at the lowest temperature. At the temperature where most of the measurements were made, $25^{\circ} \mathrm{C}$, the uncertainty range is reported to be $P_{\mathrm{v}} \pm 0.5 \%$ for the water vapor pressure measurements and $a_{\mathrm{w}} \pm 0.005(\mathrm{RH} \pm 0.5 \%)$ for the water activity.

\subsection{Comparison to particle measurement techniques}

In the literature, water activity measurements have been reported to have accuracies of $\pm 0.003-0.5$ (or $\pm 0.3-5 \%$ in terms of RH), though most recent studies are in the $\pm 0.3-$ $3 \%$ range (Zhang et al., 1993a, b; Peng et al., 2001a; Wise et al., 2003; Marcolli et al., 2004). The uncertainty range for the relative humidity in our study was within this range $\left( \pm 0.5 \%\right.$ at $\left.25^{\circ} \mathrm{C}\right)$. Reported measurement uncertainties associated with the EDB typically range from $\pm 1-5 \%$ (Cruz and Pandis, 2000; Peng et al., 2001a; Chan et al., 2005), while those associated with the HTDMA approximately vary from \pm 0.3 to $5 \%$ (Cruz and Pandis, 2000; Gysel et al., 2002; Brooks et al., 2004; Dinar et al., 2007). Our bulk method seems to have similar associated uncertainty to the particlebased methods but has the ability to study higher relative humidities.

\section{Calculation}

Several parameters were obtained for the mixed particles described in Fig. 1, calculated from measurements of bulk solutions made with equivalent compositions. The water activity $\left(a_{\mathrm{w}}\right)$ was calculated from the ratio of the water vapor pressure over the solution $\left(P_{\mathrm{v}}\right)$ to the saturation water vapor pressure $\left(P_{\mathrm{v}, \mathrm{s}}\right)$ at the same temperature,

$a_{\mathrm{w}}=\frac{\mathrm{RH}}{100 \%}=\frac{P_{\mathrm{v}}(T)}{P_{\mathrm{v}, \mathrm{s}}(T)}$.

Because the Kelvin effect was not considered in this study, the calculations in this section apply to particles $>0.10 \mu \mathrm{m}$ in diameter for the inorganic salts, levoglucosan and succinic acid, and for particles $>0.20 \mu \mathrm{m}$ in diameter for the humic substances and their mixtures. Our measured surface tension data show a Kelvin correction smaller than the associated uncertainty of water activity above these diameter values.

The mass fraction of solid in a solution was calculated as

$\mathrm{mf}_{\text {solid }}=\frac{g_{\text {solid }}}{g_{\text {solid }}+g_{\text {water }}}$.

where $g_{\text {solid }}$ is the total mass of dissolved solid from all solutes and $g_{\text {water }}$ is the mass of water in solution. The mass fraction of solid can also be expressed in percentage form, mass $\%_{\text {mix }}=\left(\mathrm{mf}_{\text {solid }}\right) \times 100$. For each solution, the mass percentage was plotted as a function of water activity and fitted with a polynomial to obtain mass $\%_{\text {mix }}=f\left(a_{\mathrm{w}}\right)$.

The hygroscopic growth factor of the mixed particles as a function of water activity was directly computed using

$G_{f, \text { mix }}\left(a_{\mathrm{w}}\right)=\left\{\frac{\mathrm{mf}_{\text {solid, dry }} \rho_{\text {mix }, \text { dry }}}{\mathrm{mf}_{\text {solid, wet }} \rho_{\text {mix, wet }}}\right\}^{\frac{1}{3}}$.

where $\mathrm{mf}_{\text {solid, dry }}$ is the mass fraction of solid in the dry particle $(=1), \mathrm{mf}_{\text {solid, wet }}$ is the mass fraction of solid in the wet particle $\left(=\right.$ mass $\left.\%_{\text {mix }} / 100\right)$, and $\rho_{\text {mix, dry }}$ and $\rho_{\text {mix, wet }}$ are the dry and wet mixed particle densities, respectively. These densities were estimated assuming that the volumes are additive when two or more compounds are mixed,

$\frac{1}{\rho_{\operatorname{mix}}}=\sum_{c} \frac{\mathrm{mf}_{c}}{\rho_{c}}$.

where $\operatorname{mf}_{c}$ and $\rho_{c}$ are the mass fraction and density of each component in solution including water for $\rho_{\text {mix, wet }}$.

For the pure solutes with known molar weight, an equation equivalent to Eq. (3) but in terms of molality was used to calculate the hygroscopic growth factor:

$G_{\mathrm{f}}\left(a_{\mathrm{w}}\right)=\left\{\frac{\rho_{\mathrm{dry}}}{\rho_{\text {wet }}}\left(1+\frac{C}{M_{\text {dry }} m_{\text {wet }}^{\mathrm{o}}}\right)\right\}^{\frac{1}{3}}$.

where $\rho_{\text {dry }}$ and $\rho_{\text {wet }}$ refer to the dry and wet particle density; $M_{\text {dry }}$ is the molar mass of the solute in $\mathrm{g} \mathrm{mol}^{-1} ; C$ is a conversion factor and equals $10^{3} \mathrm{~g}$ solute $\mathrm{kg}^{-1}$ water; and $m_{\text {wet }}^{\mathrm{o}}$ 
Table 1. Water activity parameterization of data at $25^{\circ} \mathrm{C}$, presented as molality $\left(m_{\text {wet }}^{\mathrm{o}}\right)$ versus water activity $\left(a_{\mathrm{W}}\right)$. Every coefficient $\left(b_{i}\right)$ reported in the parameterization, along with all its decimals, should be used in calculations. Note that molar weight estimates for the humic substances (Fig. 1) were used to calculate the molality of their mixtures.

\begin{tabular}{|c|c|c|c|c|c|c|c|}
\hline $\begin{array}{l}\text { Pure } \\
\text { substance/ } \\
\text { mixtures }\end{array}$ & $b_{0}$ & $b_{1} m_{\mathrm{wet}}^{\mathrm{o}}\left(a_{\mathrm{W}}\right)$ & $\begin{array}{c}=b_{0}+b_{1} a_{\mathrm{W}}+b_{2} a_{\mathrm{W}}^{2}+b_{3} \\
b_{2}\end{array}$ & ${ }_{b_{3}}^{3}+b_{4} a_{\mathrm{W}}^{4}$ & $b_{4}$ & $R^{2}$ & $\begin{array}{c}\text { Valid } \\
a_{\mathrm{W}} \\
\text { range }\end{array}$ \\
\hline $\mathrm{NaCl}$ & $-2.50228588389 \times 10^{2}$ & $1.1664316728 \times 10^{3}$ & $-1.93238829562 \times 10^{3}$ & $1.3964565467 \times 10^{3}$ & $-3.80271120120 \times 10^{2}$ & 1.00 & $0.7656-0.996$ \\
\hline$\left(\mathrm{NH}_{4}\right)_{2} \mathrm{SO}_{4}$ & $1.1403026794 \times 10^{3}$ & $-4.65485850565 \times 10^{3}$ & $7.1570190168 \times 10^{3}$ & $-4.87321859102 \times 10^{3}$ & $1.2307932385 \times 10^{3}$ & 0.99 & $0.8060-0.998$ \\
\hline Levoglucosan & $1.5456356598 \times 10^{4}$ & $-6.84006821430 \times 10^{4}$ & $1.1353711392 \times 10^{5}$ & $-8.36678814588 \times 10^{4}$ & $2.3074916883 \times 10^{4}$ & 0.99 & $0.8281-0.995$ \\
\hline Succinic aci & $1.5511340019 \times 10^{4}$ & $-3.09760273849 \times 10^{4}$ & $1.5464701255 \times 10^{4}$ & - & - & 0.99 & $0.9945-0.998$ \\
\hline NAFA-NACL & $-1.81311877890 \times 10^{2}$ & $7.4443381879 \times 10^{2}$ & $-9.31448496240 \times 10^{2}$ & $3.6838931247 \times 10^{2}$ & - & 1.00 & $0.7495-0.996$ \\
\hline NAFA-AMSL & $7.9817721954 \times 10^{1}$ & $-1.29680711802 \times 10^{2}$ & $4.9884926715 \times 10^{1}$ & - & - & 0.99 & $0.7996-0.996$ \\
\hline NAFA-LEVO & $1.1601217199 \times 10^{3}$ & $-3.51737029314 \times 10^{3}$ & $3.6420063991 \times 10^{3}$ & $-1.28556752515 \times 10^{3}$ & - & 0.99 & $0.9344-0.992$ \\
\hline NAFA-MIXORG & $1.2705186732 \times 10^{2}$ & $-1.26530481311 \times 10^{2}$ & - & - & - & 0.87 & $0.9885-1.000$ \\
\hline NAFA-MIXBIO & $1.1704218619 \times 10^{3}$ & $-2.50453513528 \times 10^{3}$ & $1.4881244434 \times 10^{3}$ & $-1.53947377827 \times 10^{2}$ & - & 0.98 & $0.9350-0.993$ \\
\hline HA-NACL & $-2.26227838908 \times 10^{2}$ & $8.3124341115 \times 10^{2}$ & $-9.68418870385 \times 10^{2}$ & $3.6363660282 \times 10^{2}$ & - & 0.99 & $0.7718-0.996$ \\
\hline HA-AMSL & $6.5541759122 \times 10^{2}$ & $-2.12590700286 \times 10^{3}$ & $2.3332104012 \times 10^{3}$ & $-8.62780467842 \times 10^{2}$ & - & 0.99 & $0.8269-1.000$ \\
\hline HA-MIXORG & $1.2205157609 \times 10^{3}$ & $-2.34042177375 \times 10^{3}$ & $1.0206394139 \times 10^{3}$ & $9.9552495632 \times 10^{1}$ & - & 0.99 & $0.9621-0.998$ \\
\hline HA-MIXBIO & $4.2086021859 \times 10^{3}$ & $-1.31796530059 \times 10^{4}$ & $1.3797001911 \times 10^{4}$ & $-4.82604748681 \times 10^{3}$ & - & 0.97 & $0.9011-0.996$ \\
\hline
\end{tabular}

is the molality of the wet particle in $\mathrm{mol} \mathrm{kg}^{-1}$ of water, which depends on its water activity $\left(a_{\mathrm{w}}\right)$.

Since our solutions are far from ideal due to large solute concentrations and electrolyte content, deviations from ideality are needed to estimate water activity as a function of composition. The van't Hoff factor $(i)$, used as a measure of solution non-ideality (Pruppacher and Klett, 1980), is defined through

$a_{\mathrm{w}}^{-1}=1+i\left(\frac{n_{\mathrm{mix}}}{n_{\mathrm{w}}}\right)$.

where $n_{\text {mix }}$ is the sum of the dissolved moles from all the solutes in solution and $n_{\mathrm{w}}$ is the moles of water in solution. Note that molar weight estimates, listed in Fig. 1, were used to calculate the number of moles for humic substances.

The ZSR method models mixed particle hygroscopic growth by assuming the particle water content is the sum of the water content associated with the pure components comprising that particle at a specific relative humidity. The following ZSR equation (Stokes and Robison, 1966; Gysel et al., 2004, Wise et al., 2003) can be used to estimate mixture growth factors using measured growth factors for the pure components

$G_{\mathrm{f}, \operatorname{mix}}\left(a_{\mathrm{w}}\right)=\left\{\sum_{i} \varepsilon_{i} G_{\mathrm{f}, i}^{3}\left(a_{\mathrm{w}}\right)\right\}^{\frac{1}{3}}$.

where $\varepsilon_{i}$ is the volume fraction of solute $i$ in the dry particle and $G_{\mathrm{f}, i}\left(a_{\mathrm{w}}\right)$ is the hygroscopic growth factor of the pure solute $i$ as a function of $a_{\mathrm{w}}$.

\section{Results and discussion}

\subsection{Pure substances}

Previously, we obtained the hygroscopic growth factor as a function of RH for several pure substances in the $0-30{ }^{\circ} \mathrm{C}$ temperature range. These solutes included those chosen for the present work: sodium chloride, ammonium sulfate, levoglucosan, succinic acid, NA fulvic acid and Fluka humic acid (HA). The $G_{f}$ values for the inorganic salts, levoglucosan, and succinic acid were in excellent agreement with published TDMA, EDB, and bulk data. However, our data for NAFA and Fluka HA indicated no hygroscopic growth up to a $\mathrm{RH}$ of $99.9 \%$, disagreeing with previous findings from particle methods. The few published TDMA (Brooks et al., 2004; Gysel et al., 2004) and EDB (Chan and Chan, 2003) studies on these solutes reported $14-66 \%$ particle growth. Data analysis and a full discussion of these results can be found in Zamora et al. (2011).

In this work, we used the relevant data on pure solutes from our previous study to provide a reference for comparison to the mixtures. Additional data on pure substances were only collected for levoglucosan in order to extend its hygroscopic growth curve at $25^{\circ} \mathrm{C}$ to a higher $\mathrm{RH}$. Using data at $25^{\circ} \mathrm{C}$, we obtained water activity parameterizations for sodium chloride, ammonium sulfate, levoglucosan, and succinic acid by fitting the molality vs. water activity data sets with fourth-degree polynomials (Fig. 3a). The resulting R-squared values, 0.999, 0.998, 0.998, and 0.991, indicate good fits of the data. Fit parameters and their associated Rsquared values are reported in Table 1. Based on the relation expressed in Eq. (6), we extracted the slope of the linear fit of the inverse water activity $\left(a_{\mathrm{w}}^{-1}\right)$ versus the ratio of moles of dissolved solute to moles of water $\left(n_{\text {mix }} / n_{\mathrm{w}}\right)$ for each solution. The resulting van't Hoff factors $(i)$ and associated R-squared values are shown in Fig. 4. The calculated $i$ for sodium chloride and ammonium sulfate, 2.58 and 2.26, 
Table 2. Water activity parameterization of data at $25^{\circ} \mathrm{C}$, presented as mass percent $\left(\%\right.$ mass $\operatorname{mix}$ ) versus water activity $\left(a_{\mathrm{W}}\right)$. Every coefficient $\left(b_{i}\right)$ reported in the parameterization, aong with all its decimals, should be used in calculations.

\begin{tabular}{|c|c|c|c|c|c|c|c|}
\hline Mixtures & $b_{0}$ & $\begin{array}{c}\% \operatorname{mas}_{\mathrm{smix}}\left(a_{\mathrm{W}}\right)= \\
b_{1}\end{array}$ & $\begin{array}{c}b_{0}+b_{1} a_{\mathrm{W}}+b_{2} a_{\mathrm{W}}^{2}+b_{3} a \\
b_{2}\end{array}$ & $\begin{array}{c}{ }_{\mathrm{V}}+b_{4} a_{\mathrm{W}}^{4}+b_{5} a_{\mathrm{W}}^{5} \\
b_{3}\end{array}$ & $b_{4} / b_{5}$ & $R^{2}$ & $\begin{array}{c}\text { Valid } \\
a_{\mathrm{W}} \\
\text { range }\end{array}$ \\
\hline NAFA-NACL & $-1.64080456310 \times 10^{3}$ & $5.9962918782 \times 10^{3}$ & $-6.96133960219 \times 10^{3}$ & $2.6062764077 \times 10^{3}$ & - & 1.00 & $0.7495-0.996$ \\
\hline NAFA-AMSL & $-4.52850505802 \times 10^{2}$ & $1.3651878078 \times 10^{3}$ & $-9.11952096415 \times 10^{2}$ & - & - & 0.99 & $0.7996-0.996$ \\
\hline NAFA-LEVO & $7.9131237987 \times 10^{6}$ & $-2.73032518103 \times 10^{7}$ & $2.8098125578 \times 10^{7}$ & $4.9057968479 \times 10^{5}$ & $\begin{array}{c}-1.56286408445 \times 10^{7} / \\
6.4300630132 \times 10^{6}\end{array}$ & 0.99 & $0.9344-0.992$ \\
\hline NAFA-MIXORG & $2.1310352837 \times 10^{3}$ & $-2.12588091039 \times 10^{3}$ & - & - & - & 0.86 & $0.9885-1.000$ \\
\hline NAFA-MIXBIO & $-9.03448168102 \times 10^{4}$ & $2.8899386978 \times 10^{5}$ & $-3.07093186201 \times 10^{5}$ & $1.0844499372 \times 10^{5}$ & - & 0.98 & $0.9350-0.993$ \\
\hline HA-NACL & $-5.10074031483 \times 10^{2}$ & $2.1069692852 \times 10^{3}$ & $-2.55599924529 \times 10^{3}$ & $9.6084272835 \times 10^{2}$ & - & 0.99 & $0.7718-0.996$ \\
\hline HA-AMSL & $-5.84059745720 \times 10^{2}$ & $1.5900333189 \times 10^{3}$ & $-1.00369411599 \times 10^{3}$ & - & - & 0.97 & $0.8269-1.000$ \\
\hline HA-MIXORG & $3.5896368745 \times 10^{4}$ & $-8.90004199515 \times 10^{4}$ & $7.0410127808 \times 10^{4}$ & $-1.73006766058 \times 10^{4}$ & - & 0.99 & $0.9621-0.998$ \\
\hline HA-MIXBIO & $4.2387029278 \times 10^{4}$ & $-1.34810029461 \times 10^{5}$ & $1.4333225570 \times 10^{5}$ & $-5.09099899404 \times 10^{4}$ & - & 0.96 & $0.9011-0.996$ \\
\hline
\end{tabular}

respectively, are in good agreement with van't Hoff factors reported in the literature of $1.93,1.87-2.93$, and 2 for $\mathrm{NaCl}$, and 2, 2.31, 2.31-2.33, and 2.47 for $\left(\mathrm{NH}_{4}\right)_{2} \mathrm{SO}_{4}$ (Low, 1969; Gerber et al., 1977; Rogers and Yau, 1989; Wise et al., 2003). The van't Hoff factor obtained for levoglucosan was 1.06, as expected from the theory and in agreement with that found by Svenningsson et al. (2006) of unity or just below. We have not included the van't Hoff factor for succinic acid in Fig. 4 since its limited solubility in water prevented the study of a wide range of $n_{\text {mix }} / n_{\mathrm{w}}$ values.

Figure 5 shows the hygroscopic growth factor as a function of water activity for these pure solutes. Each of these $G_{\mathrm{f}}$ curves was obtained by introducing the molality versus water activity expression into Eq. (5). As mentioned in the quality assurance section, the hygroscopic growth curves for sodium chloride and ammonium sulfate were in good agreement with values from published studies (Tang and Malkewitz, 1993; Cruz and Pandis, 2000). For levoglucosan, we matched hygroscopic growth factor values from published TDMA, EDB and bulk values (Mochida and Kawamura, 2004; Chan et al., 2005; Svenningsson et al., 2006) up to $a_{\mathrm{w}}=0.980$, above which we could not find available data in the literature. Note that the hygroscopic growth curve for succinic acid starts at $a_{\mathrm{w}}=0.995$, where full deliquescence was observed at $25^{\circ} \mathrm{C}$. A high deliquescence value was expected due to its limited solubility, and was in agreement with published values (Peng et al., 2001b; Wise et al., 2003; Marcolli et al., 2004; Svenningsson et al., 2006), within uncertainty. Hygroscopic growth curves are not shown for NAFA and HA since our method did not detect water uptake up to $a_{\mathrm{w}}=0.999$, and therefore $G_{\mathrm{f}}=1$ below this $a_{\mathrm{w}}$ value.

\subsection{Mixtures}

All the data reported for the mixtures were obtained during this study. First, we measured the equilibrium water vapor pressure in the $0-30{ }^{\circ} \mathrm{C}$ temperature range over the most concentrated solution we were able to prepare for each mixture. Figure $2 \mathrm{a}-\mathrm{d}$ show water activity as a function of temperature from 0 to $30^{\circ} \mathrm{C}$ for the all mixtures studied, and for saturated solutions of their individual components as reference. Equilibrium water activities were measured at $25^{\circ} \mathrm{C}$ over all subsequent dilutions of the mixtures. The water activity parameterization, van't Hoff factors and hygroscopic growth factors were calculated by inputting all the data collected at $25^{\circ} \mathrm{C}$ into the equations detailed in Sect. 3. Molality versus water activity data and their corresponding polynomial fits are shown in Fig. 3a, b, and c for pure substances, NAFA mixtures, and HA mixtures. Table 1 lists coefficients, R-squared values and valid ranges for water activity parameterization based on these fits. Table 2 includes mass-based water activity parameterizations, which excludes any molar weight assumptions for the HSs. Figure 4 shows the resulting van't Hoff factors when the slope was extracted from the linear fit of the $a_{\mathrm{w}}^{-1}$ versus $n_{\mathrm{mix}} / n_{\mathrm{w}}$ data for each solution. The hygroscopic growth factor curves as a function of water activity, along with the corresponding ZSR predictions, are shown in Figs. 5-9.

\subsubsection{Humic substances with inorganic salts}

Four aqueous mixtures were studied to explore the effect of category III organic compounds (HULIS) on the hygroscopic growth of an inorganic component. Each mixture contained one humic substance (NAFA or Fluka HA) and one inorganic salt (sodium chloride or ammonium sulfate). The compositions of these solutions (NAFA-NACL, NAFA-AMSL, HA-NACL, HA-AMSL) are shown in Fig. 1. Figure 2a and $\mathrm{b}$ show the water activity measured over these solutions in their saturated state as a function of temperature for the 0 $30^{\circ} \mathrm{C}$ range. They also show the curves for the pure saturated humic substances and inorganic salts for reference. Note that the water activity curves for saturated solutions of pure NAFA ( $25 \mathrm{wt} \%)$ and HA $(10 \mathrm{wt} \%)$ matched that of pure water, indicating no hygroscopic growth for both humic substances. While the four mixed solutions in Fig. 2a and $\mathrm{b}$ were visibly saturated with both the humic substance and the inorganic salt, their water activity curves closely mimicked those of their corresponding saturated salt solutions. This similarity to the pure salts, observed for all the tem- 

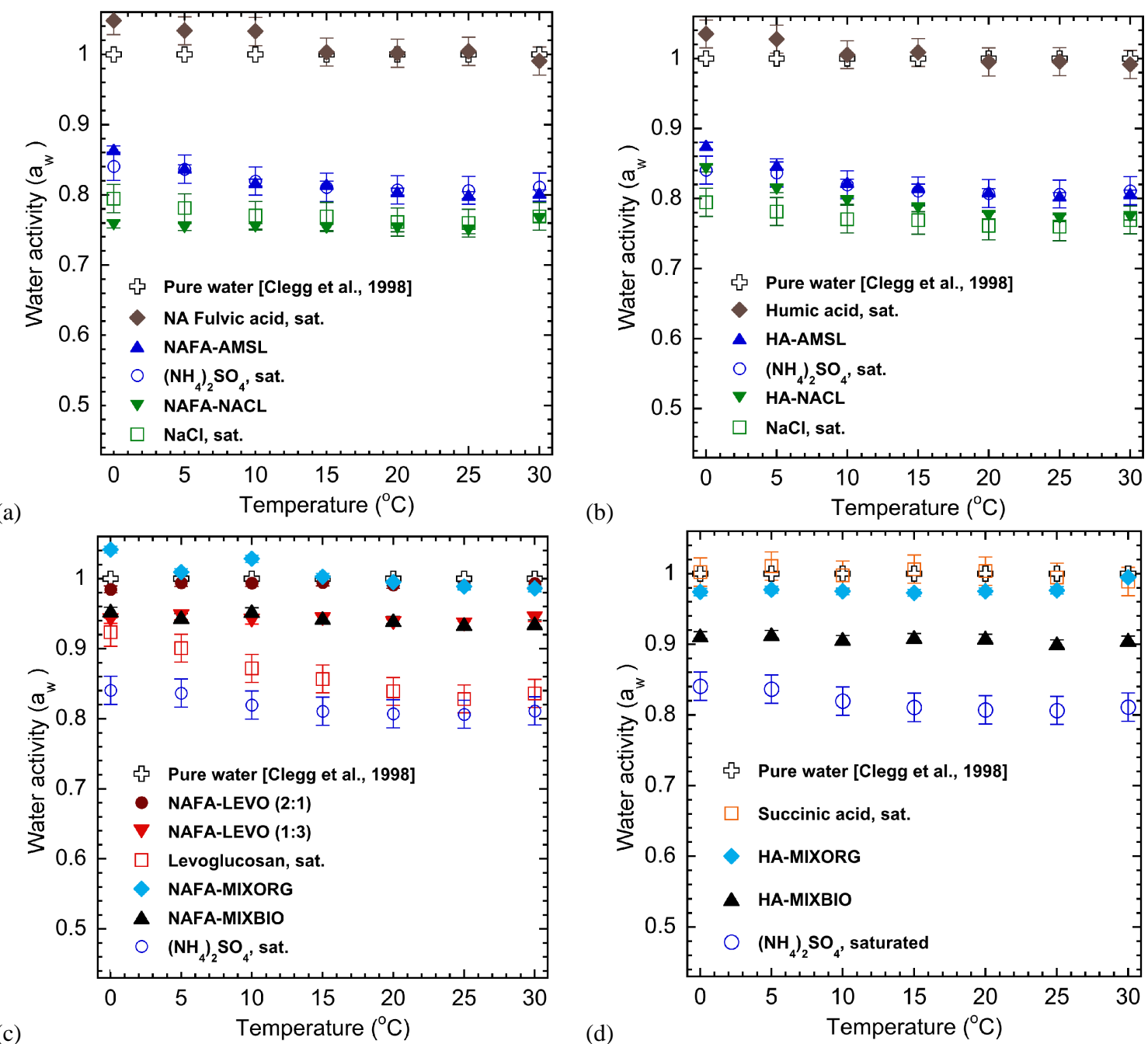

(b)

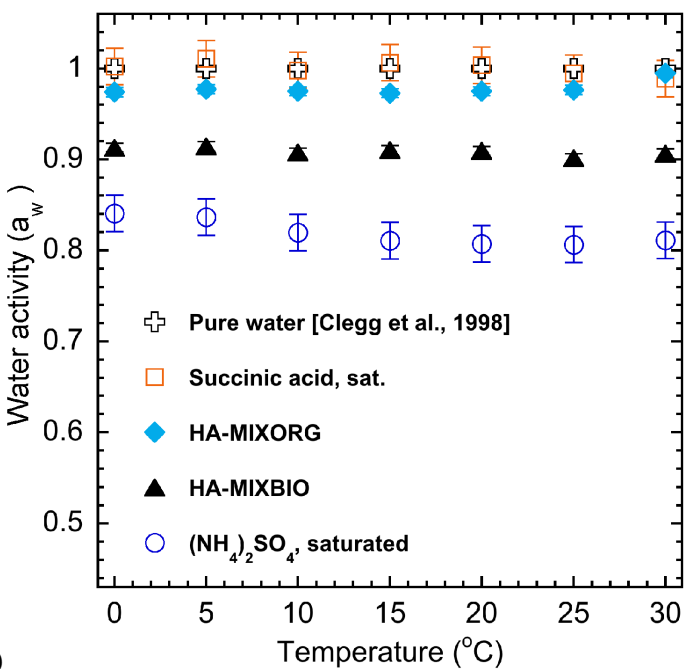

Fig. 2. Measured water activity as a function of temperature in the $0-30{ }^{\circ} \mathrm{C}$ range for the most concentrated solutions made of (a) NAFA and its mixtures with inorganic salts, (b) HA and its mixtures with inorganic salts, (c) NRFA in two mixtures with levoglucosan and in mixtures MIXORG and MIXBIO, and (d) HA in mixtures MIXORG and MIXBIO. See Fig. 1 for mixture compositions. Open symbols show the curves for pure substances at saturated concentrations measured with the same method by Zamora et al. (2011).

peratures studied, indicates that the water activity of mixtures saturated in both components was governed by the inorganic compound. For $25^{\circ} \mathrm{C}$, we looked at these water activity data to find the deliquescence point for each mixture. Adding NAFA or HA to ammonium sulfate (NAFA-AMSL, HA-AMSL) did not change its deliquescence $a_{\mathrm{w}}$ value appreciably, changing from 0.806 to 0.800 and to 0.803 , respectively. For mixtures of NAFA and HA with sodium chloride, the change in deliquescence $a_{\mathrm{w}}$ value was larger (from 0.766 to 0.750 and to 0.772 ) but still within the uncertainty range of the data for the pure salt from our previous study $\left(a_{\mathrm{w}} \pm 0.018\right)$. Similarly, Chan and Chan (2003) found that the deliquescence of 1:1 NAFA/inorganic mixtures was dominated by the inorganic species. We found the maximum variation of the water activity with temperature to be $2.2 \%$ for NAFA-NACL, $7.8 \%$ for NAFA-AMSL, $8.9 \%$ for HANACL and $8.6 \%$ for HA-AMSL, within the range studied.

The water activity parameterizations for all four mixtures are shown on Fig. 3b and c, as molality versus water activity data sets fitted with polynomials of varying orders. The polynomial coefficients, R-squared values and valid ranges for each of the parameterizations are reported in Table 1. Figure 4 shows van't Hoff factors of 2.19, 1.74, 2.74, and 2.17 for NAFA-NACL, NAFA-AMSL, HA-NACL, and HAAMSL, respectively. It is difficult to understand the dissolution behavior of the mixtures from these values because they are influenced by the molar weight assumptions made in order to calculate the moles of the humic substances. In addition, both NAFA and HA are mixtures of compounds with different molar weights, densities, and van't Hoff factors (Averett et al., 1989), and therefore their disassociation 


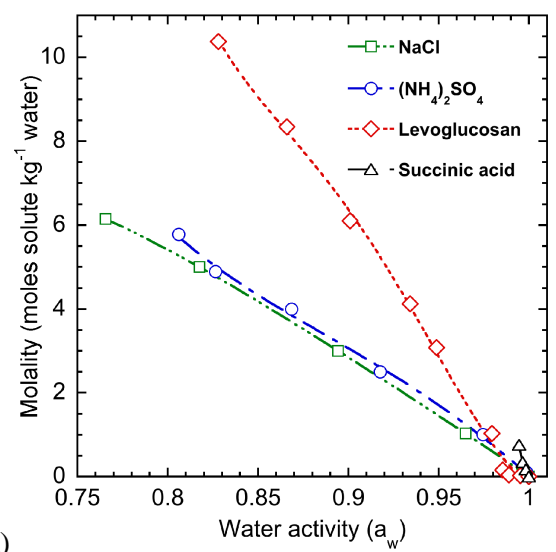

(a)

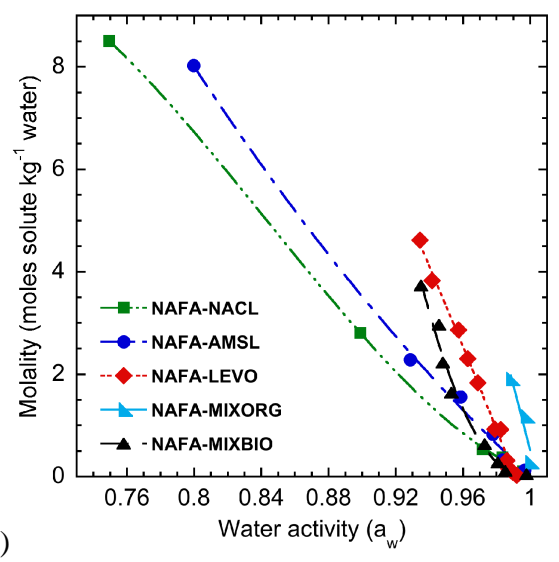

(b)

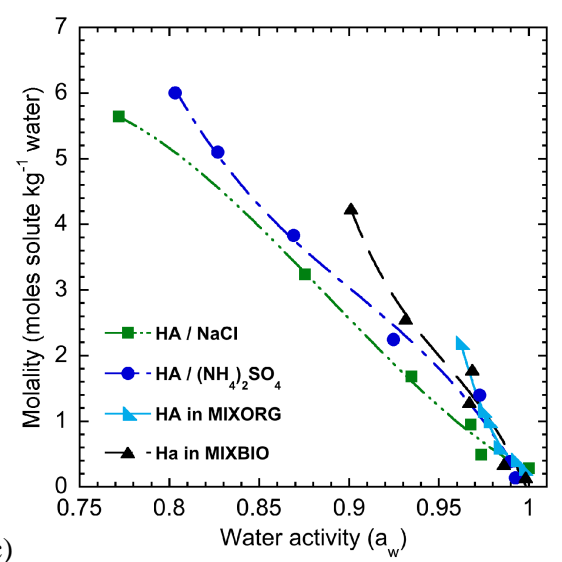

Fig. 3. Water uptake data plotted as molality versus water activity for the (a) pure substances, (b) the NAFA mixtures, and (c) the HA mixtures chosen for this study. Water activity parameterizations were obtained by fitting each data set with a polynomial (lines). Fit coefficients for all solutions are reported in Table 1. Note that the molality was calculated as the ratio of total dissolved moles for all solutes to kilograms of water added to the solution, and that molar weight estimates were used to convert mass of NAFA and HA into moles.

behavior, and van't Hoff factors, are unknown. Svenningsson et al. (2006) derived a van't Hoff factor smaller than 1 for

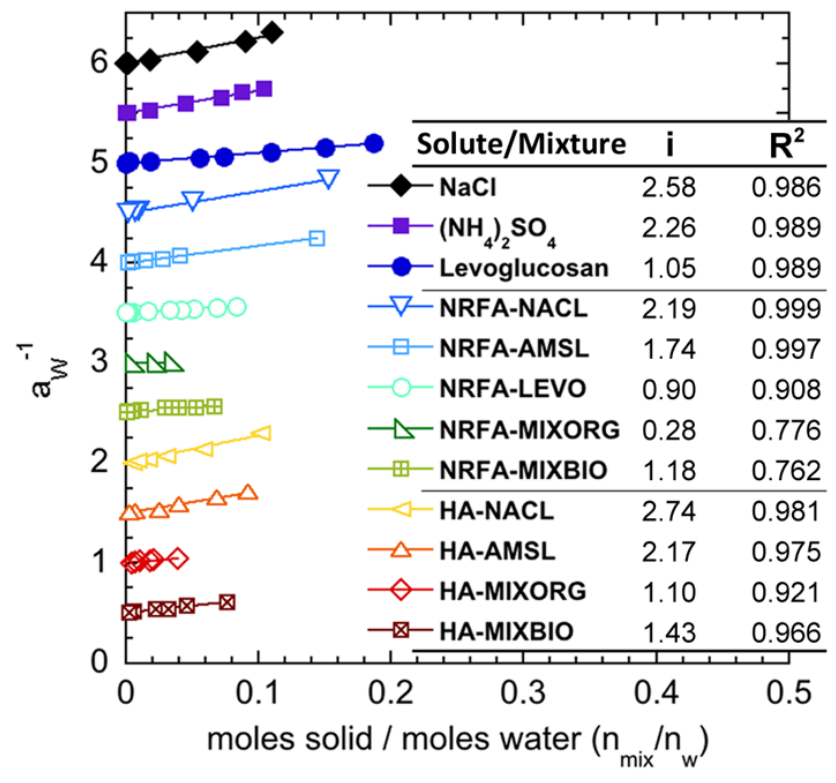

Fig. 4. Water uptake data plotted as the inverse of the water activity $\left(a_{\mathrm{W}}^{-1}\right)$ versus the ratio of moles of total dissolved solute to moles of water $\left(n_{\text {mix }} / \mathrm{n}_{\mathrm{W}}\right)$ for all solutions. A linear fit was applied to each data set. The slope of the line yields the van't Hoff factor $(i)$, which is listed along with the R-squared value for the fit. Each data set was plotted with an $a_{\mathrm{W}}^{-1}$ offset of 0.5 from the previous one for clarity.

SRFA, but noted that it was based on assumptions regarding average molar weight and density used to calculate the molality of SRFA.

The effect of adding fulvic acid and humic acid on the hygroscopic growth of the inorganic salts is easier to discern. At $25^{\circ} \mathrm{C}$, the water uptake curve obtained for each NAFA mixture was slightly smaller than that for the corresponding pure salt for most of the $a_{\mathrm{w}}$ range tested, but increased to match the salt at high $a_{\mathrm{w}}$ values. As shown in Fig. 7a, the hygroscopic growth curves for NAFA-NACL and NAFA-AMSL followed or were slightly below the ZSR prediction for each solution until $a_{\mathrm{w}}$ values of 0.90 and 0.98 , respectively. Above these values, the curves transitioned to match the hygroscopic growth of $\mathrm{NaCl}$ above $a_{\mathrm{w}}=0.95$ for NAFA-NACL, and of $\left(\mathrm{NH}_{4}\right)_{2} \mathrm{SO}_{4}$ above $a_{\mathrm{w}}=0.98$ for NAFA-AMSL. For NAFA-NACL, the ZSR curve underpredicted the growth by as much as $13 \%$ in the $0.90-0.995$ range. This underestimate of the ZSR approach at high $a_{\mathrm{w}}$ indicates possible interactions between NAFA and the inorganic salt that resulted in additional water uptake beyond that of each individual component. Since the ZSR curves are based on the data from our previous study, which found a $G_{\mathrm{f}}$ of 1 for NAFA below $a_{\mathrm{w}}=0.999$, another possibility is that our apparatus underestimated the hygroscopic growth of NAFA at high $a_{\mathrm{w}}$ values. Two studies found modest hygroscopic growth for NAFA particles at $a_{\mathrm{w}}=0.90$ : Gysel et al. (2004) found a $G_{\mathrm{f}}$ of 1.14 with a HTDMA, and Chan and Chan (2003) measured a $G_{\mathrm{f}}$ of 1.19 with an EDB. Chan and 


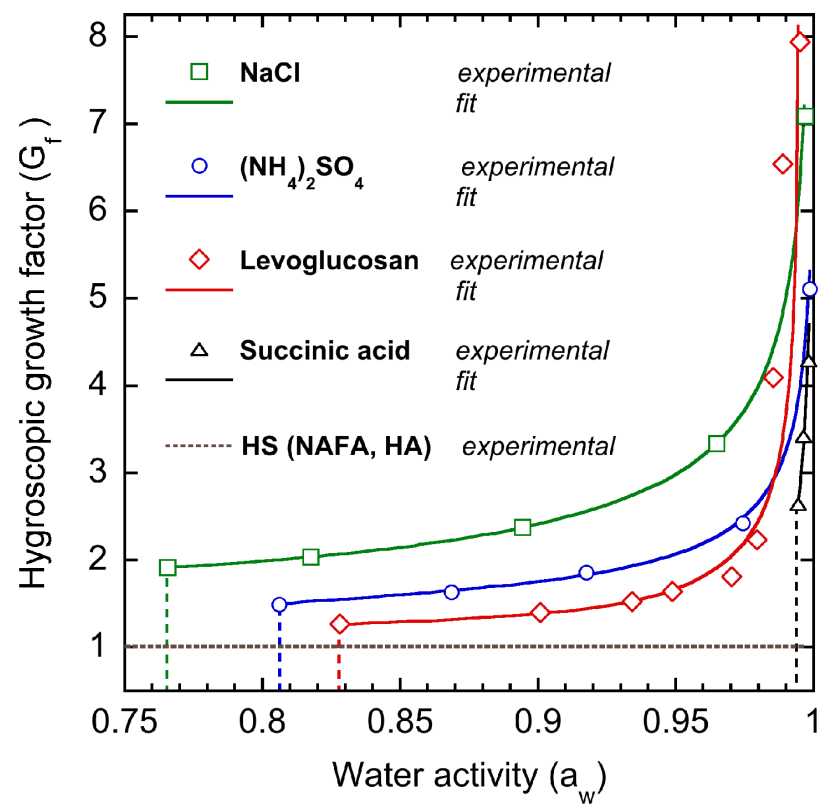

Fig. 5. Hygroscopic growth factor as a function of water activity for pure substances at $25^{\circ} \mathrm{C}$. Open symbols show the growth factors calculated from data measured by Zamora et al. (2011). Solid lines represent fits to the data based on the water activity parameterizations presented in Table 1, while vertical dashed lines denote the deliquescence $a_{\mathrm{w}}$ value. The deliquescence measured for NAFA or Fluka HA was above $a_{\mathrm{W}}=0.999$; therefore $\mathrm{G}_{\mathrm{f}}=1$ for these humic substances (HS) below this value.

Chan (2003) also measured the water uptake of mixed particles of NAFA / sodium chloride and NAFA / ammonium sulfate in a $1: 1$ mass ratio. Within experimental uncertainty, the hygroscopic growth curve for our $1: 3$ NAFA-NACL mixture agreed with the 1:1 mixture studied by Chan and Chan up to $a_{\mathrm{w}}=0.85$. By $a_{\mathrm{w}}=0.90$, the growth factor for our $1: 3$ mixture increased to be $17 \%$ higher than the $1: 1$ mixture, probably due to a higher proportion of the more hygroscopic solute, sodium chloride. The growth factors reported by Chan and Chan for the $1: 1$ NAFA-AMSL mixture were $11 \%$ higher than those we found for our $1: 3$ mixture at $a_{\mathrm{w}}=0.813$, matching the growth factor for pure ammonium sulfate. Above this value, the difference between the hygroscopic growth curves for both mixtures decreased until they intercepted at $a_{\mathrm{w}}=0.909$. In general, the water uptake data for both NAFA/inorganic salt mixtures obtained by Chan and Chan increased much more slowly than that for our mixtures, reporting up to $17 \%$ lower water uptake for NAFANACL but up to $11 \%$ higher water uptake for NAFA-AMSL. Frosch et al. (2011) also measured the water uptake of a $1: 1$ NAFA-AMSL mixture, but using an osmometer. However, they reported data for the 6-12 $G_{\mathrm{f}}$ range at $a_{\mathrm{w}}$ values above 0.9985 , which is outside of our maximum measured value of 0.9963.

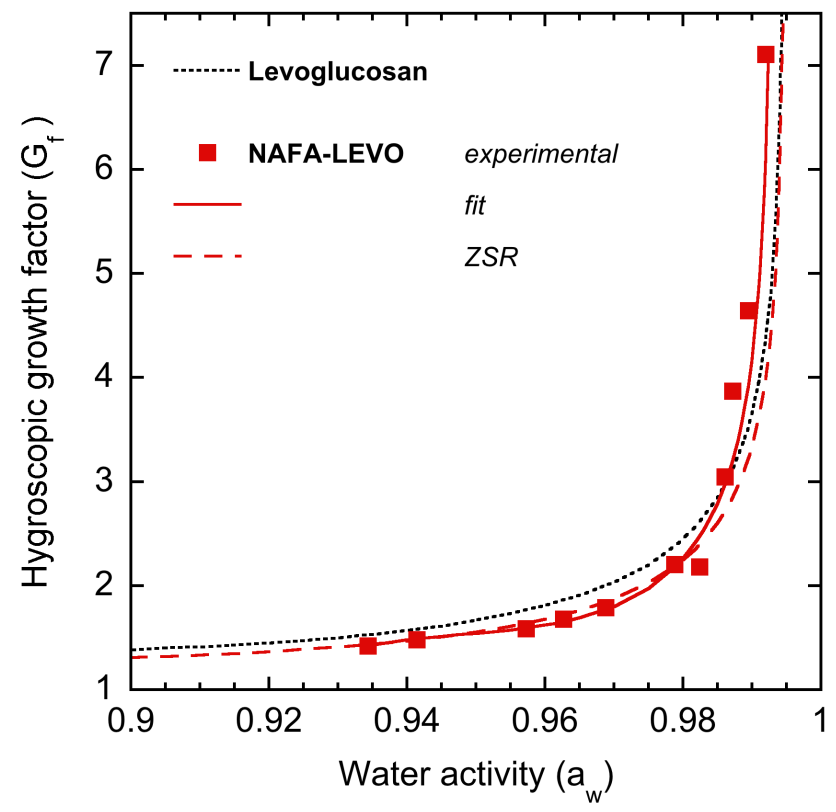

Fig. 6. Hygroscopic growth factor as a function of water activity for the NAFA-LEVO mixture at $25^{\circ} \mathrm{C}$. Solid symbols show growth factors calculated from bulk solution measurements using Eq. (3). The solid line represents the fit to the data based on the water activity parameterizations presented in Table 1 . The dashed line denotes the hygroscopic growth factor as predicted by the ZSR method. The curve for pure levoglucosan (dotted line) is given for reference.

The hygroscopic growth curves of HA-NACL and HAAMSL at $25^{\circ} \mathrm{C}$ are presented in Fig. $7 \mathrm{~b}$. The water uptake obtained for each HA mixture was smaller than that for the corresponding pure salt in proportion to the mass added of the organic species. This suggests that humic acid did not contribute any hygroscopic growth, as expected from its previous data as an individual solute. Thus, the curves agreed well with their respective ZSR predictions throughout the measured range. Within uncertainty, our data for HA-AMSL matched that obtained by Brooks et al. (2004) with the HTDMA for the $1: 9$ and $1: 1$ Fluka HA/ammonium sulfate particles in the $a_{\mathrm{w}}$ range of 0.80 to 0.92 , where the data overlap.

\subsubsection{Fulvic acid with levoglucosan}

The mixture NAFA-LEVO was prepared with NAFA and levoglucosan in a $1: 3$ mass ratio (Fig. 1). An additional mixture was made with a $2: 1$ NAFA / levoglucosan mass ratio to determine further the influence of fulvic acid on the hygroscopic growth of a category I compound. Figure $2 \mathrm{c}$ shows the water activity curves for both mixtures, along with that for a saturated solution of pure levoglucosan as reference. The water activity measurements for the $2: 1$ NAFA/levoglucosan mixture were $0.5-1.5 \%$ lower than the measurements for pure water, a difference within or barely above our experimental error, while those obtained for $1: 3$ NAFA-LEVO 


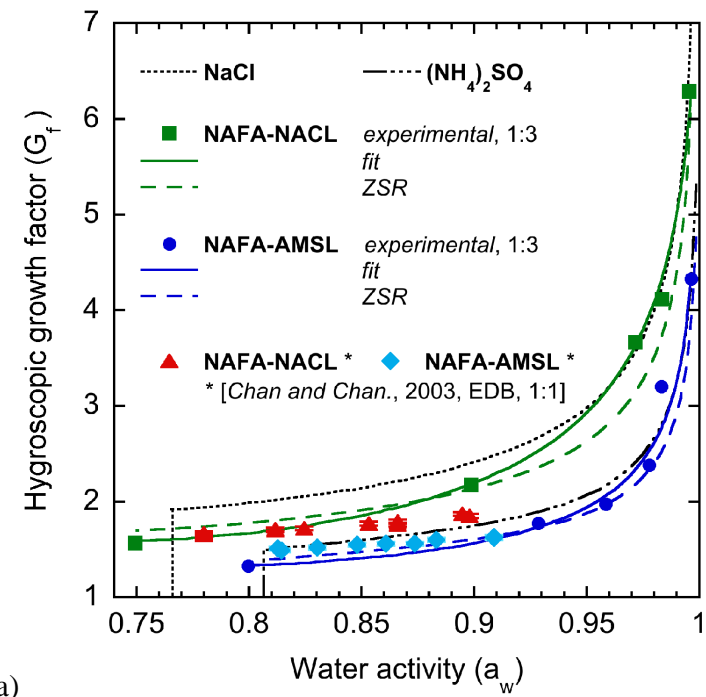

(a)

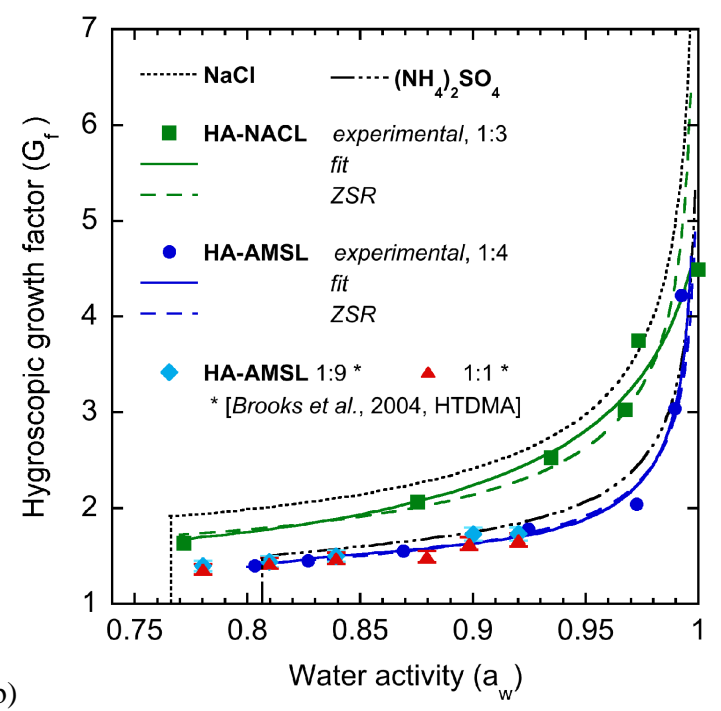

Fig. 7. Hygroscopic growth factor as a function of water activity at $25^{\circ} \mathrm{C}$ for the mixture of inorganic salts with (a) NAFA, and (b) HA. Solid symbols show growth factors calculated from bulk solution measurements using Eq. (3). Solid lines represent the fit to the data based on the water activity parameterizations presented in Table 1, while dashed lines denote the hygroscopic growth factor as predicted by the ZSR method. The curves for pure sodium chloride (dotted line) and ammonium sulfate (dotted-dashed line), including their deliquescence points (vertical lines), are given for reference. Published data for similar mixtures was included: (a) EDB measurements by Chan and Chan (2003) at $22.5-23.8^{\circ} \mathrm{C}$, and (b) HTDMA data by Brooks et al. (2004) at $30^{\circ} \mathrm{C}$.

were $5.0-6.7 \%$ lower. Both mixtures behaved very similarly to pure solutions with equivalent mass percentage of levoglucosan, indicating that the saccharide had the largest influence by far on the water vapor pressure over the solution. Unfortunately, the DRHs of these mixtures were not measured since solutions saturated in both solutes could not

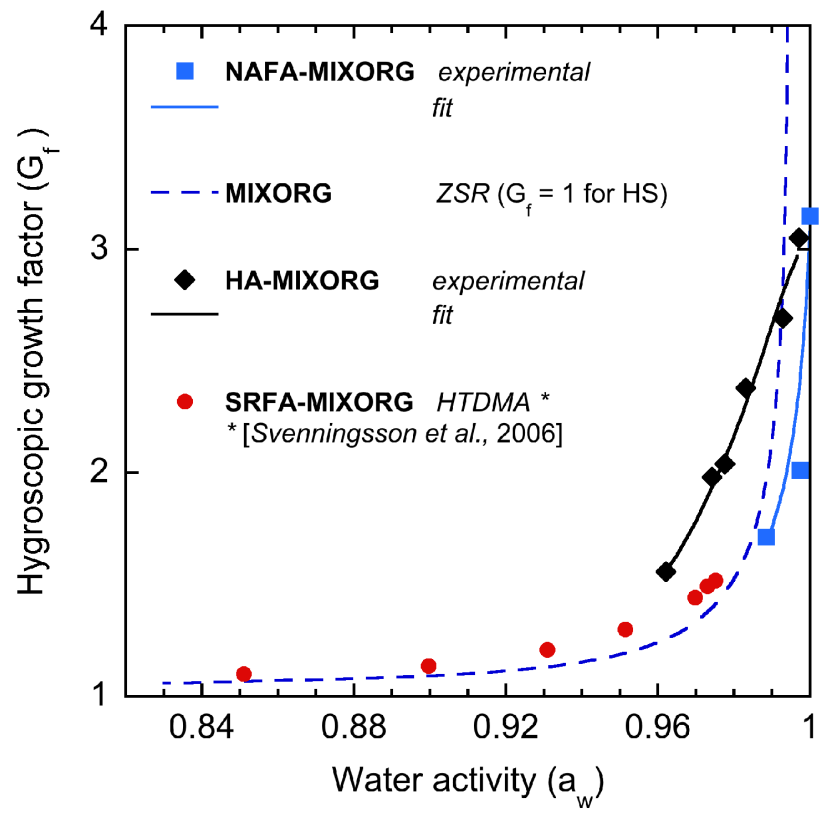

Fig. 8. Hygroscopic growth factor as a function of water activity for NAFA and HA in MIXORG at $25^{\circ} \mathrm{C}$. Solid symbols show growth factors calculated from bulk solution measurements using Eq. (3). Solid lines represent the fit to the data based on the water activity parameterizations presented in Table 1 . Red solid circles show HTDMA data at $21-24^{\circ} \mathrm{C}$ for Suwannee River fulvic acid (SRFA) in MIXORG from published work by Svenningsson et al. (2004). The dashed line denotes the prediction by the ZSR approach for MIXORG containing NAFA, HA or SRFA, based on no hygroscopic growth observed for these HS below $a_{\mathrm{W}}$ of 0.999 in Zamora et al. (2011).

be prepared. The large quantity of NAFA required to prepare these saturated solutions, given the high aqueous solubility of levoglucosan, was not available due to IHSS sample purchase limits. The water activity varied only slightly with temperature in the $0-30{ }^{\circ} \mathrm{C}$ temperature range, with maximum variations of $1.0 \%$ for $2: 1$ NAFA-LEVO and $1.3 \%$ for $1: 3$ NAFA-LEVO. Further measurements of the diluted solutions at $25^{\circ} \mathrm{C}$ were only conducted on $1: 3$ NAFA-LEVO.

The solution molality versus water activity data for NAFA-LEVO was plotted and fitted with a 5th-degree polynomial to obtain its water activity parameterization. The corresponding polynomial coefficients, R-squared values and valid ranges are listed in Table 1. Figure 4 shows a van't Hoff factor of 0.90 for NAFA-LEVO, suggesting that this mixture behaves close to an ideal solution. The addition of fulvic acid slightly lowered the van't Hoff factor of NAFALEVO, as compared to that of levoglucosan. A similar effect was observed on the mixtures of NAFA with the inorganic salts.

Figure 6 shows our experimental data and the ZSR model prediction for the hygroscopic growth factor as a function of water activity for NAFA-LEVO. It also shows the water 


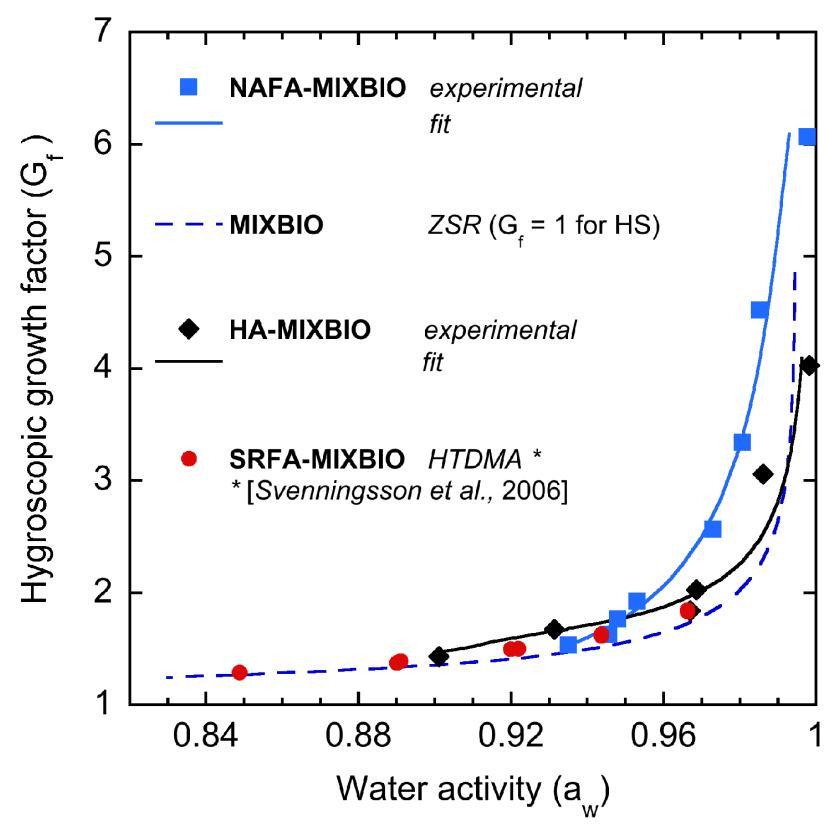

Fig. 9. Hygroscopic growth factor as a function of water activity for NAFA and HA in MIXBIO at $25^{\circ} \mathrm{C}$. Solid symbols show growth factors calculated from bulk solution measurements using Eq. (3). Solid lines represent the fit to the data based on the water activity parameterizations presented in Table 1 . Red solid circles show HTDMA data at $21-24{ }^{\circ} \mathrm{C}$ for Suwannee River fulvic acid (SRFA) in MIXBIO from published work by Svenningsson et al. (2004). The dashed line denotes the prediction by the ZSR approach for MIXORG containing NAFA, HA or SRFA, based on no hygroscopic growth observed for these HS below $a_{\mathrm{w}}$ of 0.999 in Zamora et al. (2011).

uptake curve for pure levoglucosan for comparison. The hygroscopic growth curve of NAFA-LEVO matched the ZSR prediction up to $a_{\mathrm{w}}=0.98$, which predicted values up to $10 \%$ lower than pure levoglucosan. At 0.986 , the NAFALEVO curve intersected that of pure levoglucosan, which joins with the ZSR curve above $a_{\mathrm{w}}=0.9933$. The water uptake curve of NAFA-LEVO shifted left by $0.002-0.004$ water activity values above the point where it met the curve for pure levoglucosan, which is within our experiment uncertainty range of $a_{\mathrm{w}} \pm 0.005$. In sum, the NAFA-LEVO mixture presented growth factors up to $10 \%$ lower than pure levoglucosan below $a_{\mathrm{w}}=0.98$, as predicted by the ZSR method. Above 0.98 , it agreed well with pure levoglucosan and the ZSR approach within experimental error.

\subsubsection{MIXORG}

MIXORG is a mixture of three organic compounds: levoglucosan, succinic acid and one humic substance, in proportions representative of the organic portion of continental polluted aerosols (Fig. 1). Figure 2c and d show the water activity versus temperature, in the $0-30{ }^{\circ} \mathrm{C}$ range, for the most concentrated solutions of MIXORG made. These figures also show the curves for the saturated solutions of pure levoglucosan, succinic acid, and ammonium sulfate as reference. The MIXORG mixtures had a minimal effect on the water activity, as expected from $80 \%$ of their mass being comprised of two substances that had little or no effect on the water vapor pressure over their pure saturated solutions. $\mathrm{Al}-$ though these solutions were saturated with respect to fulvic and humic acid, respectively, saturated solutions with respect to all solutes could not be prepared due to the large quantities of solutes required by the high solubility of levoglucosan. Hence, the deliquescence relative humidity for these mixtures could not be determined. Within the temperature range studied, the maximum water activity variation with temperature was $5.4 \%$ for NAFA-MIXORG and $2.2 \%$ for HA-MIXORG.

Table 1 lists the polynomial coefficients, R-squared values and valid ranges for the water activity parameterization fits for the MIXORG mixtures. The van't Hoff factors obtained for NAFA-MIXORG and HA-MIXORG were 0.28 and 1.10, respectively (Fig. 4). Assuming our molar weight estimates for the humic substances are accurate, these values indicate that HA-MIXORG behaved almost ideally, while NAFA-MIXORG appeared to deviate substantially from ideality. It is worth noting that due to solubility issues with succinic acid, the factor for NAFA-MIXORG incorporates considerably less data points than all other solutions presented and therefore is a not reliable indication of ideality or dissociation levels.

Figure 8 shows the hygroscopic growth factor obtained for NAFA-MIXORG and HA-MIXORG, as a function of water activity. The curve generated with the ZSR model is also shown. Only one ZSR curve was included because both solutions have individual components with identical water uptake. Both NAFA and HA presented no hygroscopic growth as pure solutes in our previous study, and thus $G_{\mathrm{f}}=1$ for all water activity values under 0.999 . The curve for HAMIXORG presented much higher hygroscopic growth than the ZSR approach predicted but increased at a lower rate, which led to the intersection of the curves at $a_{\mathrm{w}}=0.99$. This underprediction of the ZSR method under $a_{\mathrm{w}}=0.99$ may indicate that solute interactions are contributing additional hygroscopic growth to that expected from its individual components. The water uptake curve for HA-MIXORG was obtained for a maximum solution concentration equivalent to a growth factor of 1.5 , due to the solubility constraints on solution preparation mentioned above. The curve appears almost linear above this $G_{\mathrm{f}}$ value, consistent with the steeper section of the typical hygroscopic growth curve at higher $a_{\mathrm{w}}$ values. The NAFA-MIXORG mixture presented a growth factor $42 \%$ smaller than HA-MIXORG, and $21 \%$ smaller than the ZSR prediction at $a_{\mathrm{w}}=0.99$.

Figure 8 also shows the data collected by Svenningsson et al. (2006) with the HTDMA for the SRFA-MIXORG mixture. The ZSR method shown in their study, which accounted for the 5-13\% hygroscopic growth they observed for SRFA 
particles between 0.85 and $0.95 a_{\mathrm{w}}$, agreed well with these data. Our ZSR curve for both MIXORG mixtures also applies for SRFA-MIXORG since we obtained no growth for saturated solutions of SRFA in our previous study (Zamora et al., 2011). It predicts the data from the Svenningsson study reasonably well with a maximum underestimation of $8.0 \%$. One of the reasons for using two of the same mixtures used in Svenningsson et al. (2006) was to be able to compare the water uptake of different humic substances in mixtures of identical composition. Unfortunately, the hygroscopic growth data for the fulvic acid mixtures were not obtained in the same water activity range due to the limitations of HTDMA at higher RHs, and of our method to achieve higher concentrations in bulk solutions. However, the data for HA-MIXORG and SRFA-MIXORG overlapped for a small range of water activity, where HA-MIXORG had a 21.4 and $26.3 \%$ higher growth factor at $a_{\mathrm{w}}$ of 0.960 and 0.975 , respectively.

\subsubsection{MIXBIO}

The MIXBIO mixture is composed of ammonium sulfate, levoglucosan, succinic acid, and a humic substance in proportions representative of biomass burning aerosols (Fig. 1). Figure $2 \mathrm{c}$ and $\mathrm{d}$ show the water activity versus temperature, for the most concentrated solutions of MIXBIO made, in the $0-30{ }^{\circ} \mathrm{C}$ range. As expected, the MIXBIO solutions had lower water activity curves than the MIXORG solutions containing the same humic substance due to the hygroscopic effect of ammonium sulfate. However, due to the quantity of mass of NAFA and HA required to make the bulk solutions, saturated solutions with respect to all solutes in MIXBIO could not be prepared. Therefore, the maximum effect on the vapor pressure and the deliquescence relative humidity for these mixtures could not be determined. The greatest water activity variation with temperature, within the $0-30{ }^{\circ} \mathrm{C}$ range, was 2.0 and $1.5 \%$ for NAFA-MIXBIO and HA-MIXBIO, respectively.

The polynomial coefficients, R-squared values and valid ranges for the water activity parameterization fits for both MIXBIO mixtures are reported on Table 1. Figure 4 shows a van't Hoff factor of 1.18 for NAFA-MIXBIO, and of 1.43 for HA-MIXBIO. As stated above, the molar weight estimates for the humic substances will affect the van't Hoff factor calculation. Still, if we assume the estimates used are correct, MIXBIO containing NAFA behaves more like an ideal solution than does HA, since the former's van't Hoff factor is closer to one. The opposite was found for the MIXORG mixtures.

Figure 9 shows the hygroscopic growth factor obtained for NAFA-MIXBIO and HA-MIXBIO as a function of water activity. The ZSR model curve, also shown in Fig. 9, is applicable to NAFA-MIXBIO and HA-MIXBIO since their only difference is the addition of NAFA versus HA, both of which presented no hygroscopic growth as pure solutes $\left(G_{\mathrm{f}}=1\right.$ for all $a_{\mathrm{w}}$ values). The hygroscopic growth curve of HA-MIXBIO was 11-13\% higher than the ZSR prediction, although it followed its general trend and followed its curve above $a_{\mathrm{w}}=0.99$. NAFA-MIXBIO presented a much higher hygroscopic growth, exceeding the ZSR prediction by $13 \%$ and $48 \%$ at $a_{\mathrm{w}}=0.95$ and 0.98 , respectively. Such a deviation from the ZSR method indicates interactions of NAFA with the other solution components that resulted in significant additional hygroscopic growth to that expected from the individual components. However, the data from the $1: 3 \mathrm{NAFA} /$ ammonium sulfate and $1: 3$ NAFA/levoglucosan systems did not suggest interactions among those solute pairs large enough to justify the growth observed in NAFA-MIXBIO. Since the NAFA-MIXORG mixture presented minimal water uptake, it seems likely that the additional water uptake above the ZSR calculation for NAFA-MIXBIO was caused by a multicomponent interaction between NAFA, ammonium sulfate and one or both of the remaining components: levoglucosan and succinic acid.

We have also included in Fig. 9 data collected by Svenningsson et al. (2006) with the HTDMA for the SRFAMIXBIO mixture for comparison. These data were bounded on top by the ZSR curve shown in their study, which accounted for the small growth they observed for pure SRFA particles and for the limited solubility of succinic acid. Our ZSR curve for MIXBIO, which is also applicable for SRFA since we obtained no growth for its saturated solutions in our previous study, provides a lower bound for the data. Although Svenningsson et al. (2006) mentioned that the small overestimation resulted from taking into account the solubility of succinic acid, there may be alternative explanations. The over- and underestimation with our respective ZSR models might indicate that the individual water uptake of SRFA in the MIXBIO mixture is slightly lower than expected from the HTDMA measurements but higher than expected from the bulk measurements of the pure solute. Another possibility is that interactions between SRFA and the other components are producing these small deviations from ZSR.

Since all three MIXBIO mixtures have identical composition except for the identity of humic substance, we can compare their hygroscopic behavior directly. HA-MIXBIO and SRFA-MIXBIO shared the same hygroscopic growth factor at $a_{\mathrm{w}}=0.90$, but HA-MIXBIO presented slightly higher growth above that value. The water uptake data for the fulvic acid mixtures overlapped briefly from 0.935 to $0.945 a_{\mathrm{w}}$, but NAFA-MIXBIO showed a sharp increase in water uptake above this value, reaching a growth factor $22 \%$ higher than the last $G_{\mathrm{f}}$ reported for SRFA-MIXBIO at $a_{\mathrm{w}}=0.966$.

\section{Conclusions}

This study presented new water activity parameterizations that can be used to describe the water uptake of mixed aerosol particles, in a format easy to incorporate into atmospheric models. These parameterizations were generated 
from bulk water vapor pressure measurements of nine mixtures of atmospheric relevance. These mixtures consisted of two inorganic salts and four model compounds representing different categories of water-soluble organic carbon (WSOC). The WSOC categories of neutral species and dicarboxylic acids were represented by levoglucosan and succinic acid, respectively. HULIS was represented by two humic substances (HSs): Nordic aquatic fulvic acid and Fluka humic acid. We calculated the hygroscopic growth factor as a function of water activity at $25^{\circ} \mathrm{C}$ for each mixture, and compared it to the ZSR model prediction, and to the few relevant published studies available.

We investigated the effect of HULIS on the water uptake of three different hygroscopic solutes (sodium chloride, ammonium sulfate, and levoglucosan), using five twocomponent solutions. Within the $0-30^{\circ} \mathrm{C}$ range, the water vapor pressures over each of these mixtures were governed by the hygroscopic compound. Below $95 \% \mathrm{RH}$, the addition of NA fulvic acid or humic acid to each of these highly water-soluble solutes lowered their hygroscopic growth, in proportion to the added mass of HS. Yet, only the hygroscopic growth of the mixtures containing fulvic acid transitioned to match the growth of the pure salt or saccharide at higher RHs values.

We also examined the hygroscopic behavior of these two HSs in mixtures based on recent aerosol characterization experiments of biomass burning (MIXBIO) and of the organic portion of the polluted continental (MIXORG) aerosols. We compared our results with the hygroscopic growth of Suwannee River fulvic acid in the same mixtures, measured by Svenningsson et al. (2004) with the HTDMA. MIXORG exhibited higher hygroscopic growth when containing humic acid than when containing Suwannee River or Nordic aquatic fulvic acids. Conversely, MIXBIO showed a much higher water uptake with solute Nordic aquatic fulvic acid as compared to solutes humic acid or Suwannee River fulvic acid. Each of these three humic substances affected the hygroscopic growth of mixtures differently, despite two being fulvic acids frequently used as model compounds for HULIS. Above $95 \% \mathrm{RH}$, the relative water uptake of identical mixtures containing different HSs varied significantly among the mixtures studied and could not be predicted by the hygroscopic growth of the pure HS, suggesting interactions among components. This is consistent with findings from Brooks et al. (2004) and Chan and Chan (2003), which found differences in the hygroscopic behavior of identical mixtures containing two different humic acids and two fulvic acids, respectively.

We obtained van't Hoff factors for all the mixtures studied, and for the pure substances for which there was sufficient data range. As expected from their low disassociation, all mixtures comprised entirely of organic solutes had a van't Hoff factor near 1 except for NAFA-MIXORG. The addition of NAFA to mixtures resulted in lower van't Hoff factors than their pure components, assuming that succinic acid had a van't Hoff factor near 1 . No such pattern was evident for HA mixtures.

We explored the effect of temperature in the $0-30{ }^{\circ} \mathrm{C}$ range on water activity for our nine mixtures. In our previous study, we found that the temperature had a small influence on water activity measurements in the same range, with a maximum variation of $11 \%$ for the substances included in this work (Zamora et al., 2011). In the present work, the largest water activity variation with temperature observed in the $0-30{ }^{\circ} \mathrm{C}$ range for the mixtures studied was $9 \%$. Further analysis on the data for room temperature $\left(20-30^{\circ} \mathrm{C}\right)$, the range at which most water uptake measurements are collected, yielded a maximum variation of only $2 \%$. This variation is within the uncertainty range for the water activity (or RH) of several published studies. Thus, measurements obtained within the room temperature range of $20-30^{\circ} \mathrm{C}$ may be compared directly with more confidence.

Finally, we assessed the ability of the ZSR model to predict the hygroscopic growth of the nine mixtures studied. The ZSR worked reasonably well for six of the nine mixtures: three NAFA mixtures (NAFA-LEVO, NAFA-AMSL, NAFA-MIXORG) and three HA mixtures (HA-NACL, HAAMSL, HA-MIXBIO). In general, the ZSR method predicted the hygroscopic behavior of all the mixtures studied in this work within $12 \%$ at or under $a_{\mathrm{w}}=0.95$ but considerably underestimated the growth of two multicomponent mixtures at very high $a_{\mathrm{w}}$ values.

Overall, we have shown that the effect of humic substances on the hygroscopic behavior of atmospheric aerosols can vary widely depending on the identity and origin of the humic substance. We confirmed evidence from previous studies that the ZSR method works well for two-component mixtures containing an organic and an inorganic solute and extended this assertion to $a_{\mathrm{w}}$ values above 0.95 , where it has rarely been tested. We have also demonstrated that the ZSR approach works reasonably well for the multicomponent mixtures studied under $a_{\mathrm{w}}=0.95$, but can produce large deviations at higher values. Based on our findings, we recommend that similar studies be performed with an analog more representative of HULIS in place of humic substances. One option could be to use chamber-generated secondary organic aerosols (SOA), in order to better represent the influence of HULIS in the hygroscopic growth of atmospheric particles. However, we recognize this approach may not yet be suitable for bulk studies. It is likely that the quantity of SOA residue required to prepare the bulk solutions needed would exceed the amount that could be generated in a smog chamber. Although it may be possible to design a process to collect enough SOA from multiple chamber runs, reproducibility would be a concern. Another option would be to find a substitute chemical for HULIS. A bulk HULIS analog should ideally have uniform properties from batch to batch, a known molecular weight, and similar surface activity and aromatic moiety content to HULIS. While the search for a better HULIS representative is ongoing, additional studies 
with humic substances can still provide insight into the behavior or multicomponent mixtures in atmospheric aerosols.

Acknowledgements. We gratefully acknowledge the School of Earth Sciences at Stanford University and the atmospheric chemistry division of the National Science Foundation for support. We would also like to thank D. M. Golden and L. M. Hildemann for helpful discussions.

Edited by: D. Topping

\section{References}

Alfarra, M. R., Paulsen, D., Gysel, M., Garforth, A. A., Dommen, J., Prévôt, A. S. H., Worsnop, D. R., Baltensperger, U., and Coe, H.: A mass spectrometric study of secondary organic aerosols formed from the photooxidation of anthropogenic and biogenic precursors in a reaction chamber, Atmos. Chem. Phys., 6, 52795293, doi:10.5194/acp-6-5279-2006, 2006.

Alshawa, A., Dopfer, O., Harmon, C. W., Nizkorodov, S. A., and Underwood, J. S.: Hygroscopic growth and deliquescence of $\mathrm{NaCl}$ nanoparticles coated with surfactant AOT, J. Phys. Chem. A, 113, 7678-7686, doi:10.1021/jp809869r, 2009.

Andreae, M. O. and Crutzen, P. J.: Atmospheric aerosols: Biogeochemical sources and role in atmospheric chemistry, Science, 276, 1052-1058, doi:10.1126/science.276.5315.1052, 1997.

Artaxo, P., Storms, H., Bruynseels, F., Vangrieken, R., and Maenhaut, W.: Composition and sources of aerosols from the Amazon basin, J. Geophys. Res.-Atmos., 93, D2, doi:10.1029/JD093iD02p01605, 1988.

Artaxo, P., Maenhaut, W., Storms, H., and Vangrieken, R.: Aerosol characteristics and sources for the amazon basin during the wet season, J. Geophys. Res.-Atmos., 95, 1697-16985, doi:10.1029/JD095iD10p16971, 1990.

Artaxo, P., Martins, J. V., Yamasoe, M. A., Procopio, A. S., Pauliquevis, T. M., Andreae, M. O., Guyon, P., Gatti, L. V., and Leal, A. M. C.: Physical and chemical properties of aerosols in the wet and dry seasons in Rondonia, Amazonia, J. Geophys. Res.-Atmos., 107, LBA 49-1-LBA 49-14, doi:10.1029/2001jd000666, 2002.

Averett, R. C., Leenheer, J. A., McKnight, D. M., and Thorn, K. A.: Humic substances in the Suwannee River, Georgia: interactions, properties, and proposed structures, Open-File Report-US Geological Survey, 1989.

Badger, C. L., George, I., Griffiths, P. T., Braban, C. F., Cox, R. A., and Abbatt, J. P. D.: Phase transitions and hygroscopic growth of aerosol particles containing humic acid and mixtures of humic acid and ammonium sulphate, Atmos. Chem. Phys., 6, 755-768, doi:10.5194/acp-6-755-2006, 2006.

Bond, T. C., Streets, D. G., Yarber, K. F., Nelson, S. M., Woo, J. H., and Klimont, Z.: A technology-based global inventory of black and organic carbon emissions from combustion, J. Geophys. Res.-Atmos., 109, D14, doi:10.1029/2003jd003697, 2004.

Brooks, S.: Deliquescence behavior of organic/ammonium sulfate aerosol, Geophys. Res. Lett., 29, 23-1-23-4, doi:10.1029/2002g1014733, 2002.

Brooks, S.: Water uptake by particles containing humic materials and mixtures of humic materials with ammonium sulfate, Atmos.
Environ., 38, 1859-1868, doi:10.1016/j.atmosenv.2004.01.009, 2004.

Chan, M. N. and Chan, C. K.: Hygroscopic properties of two model humic-like substances and their mixtures with inorganics of atmospheric importance, Environ, Science Technol., 37, 51095115, doi:10.1021/es034272o, 2003.

Chan, M. N., Choi, M., Ng, N., and Chan, C.: Hygroscopicity of water-soluble organic compounds in atmospheric aerosols: amino acids and biomass burning derived organic species, Environ. Science Technol., 39, 1555-1562, doi:10.1021/es0495841, 2005.

Chebbi, A. and Carlier, P.: Carboxylic acids in the troposphere, occurrence, sources, and sinks: A review, Atmos. Environ., 30, 4233-4249, doi:10.1016/1352-2310(96)00102-1, 1996.

Choi, M. Y. and Chan, C. K.: The effects of organic species on the hygroscopic behaviors of inorganic aerosols, Environmental Science \& Technology, 36, 2422-2428, doi:10.1021/es0113293, 2002a.

Choi, M. Y. and Chan, C. K.: Continuous measurements of the water activities of aqueous droplets of water-soluble organic compounds, J. Phys. Chem. A, 106, 4566-4572, doi:10.1021/jp013875o, 2002b.

Clegg, S. L., Brimblecombe, P., and Wexler, A. S.: Thermodynamic model of the system $\mathrm{H}-\mathrm{NH}-\mathrm{Na}-\mathrm{SO}_{42}-\mathrm{NO}_{3}-\mathrm{Cl}-\mathrm{H}_{2} \mathrm{O}$ at 298.15 K, J. Phys. Chem. A, 102, 2155-2171, doi:10.1021/jp973043j, 1998.

Cruz, C. N. and Pandis, S. N.: Deliquescence and hygroscopic growth of mixed inorganic-organic atmospheric aerosol, Environ. Science Technol., 34, 4313-4319, doi:10.1021/es9907109, 2000.

Decesari, S., Facchini, M. C., Matta, E., Lettini, F., Mircea, M., Fuzzi, S., Tagliavini, E., and Putaud, J. P.: Chemical features and seasonal variation of fine aerosol water-soluble organic compounds in the Po Valley, Italy, Atmos. Environ., 35, 3691-3699, doi:10.1016/s1352-2310(00)00509-4, 2001.

Decesari, S., Facchini, M. C., Fuzzi, S., McFiggans, G., Coe, H., and Bower, K.: The water-soluble organic component of size-segregated aerosol, cloud water and wet depositions from Jeju Island during ACE-Asia, Atmos. Environ., 39, 211-222, doi:10.1016/j.atmosenv.2004.09.049, 2005.

Dinar, E., Taraniuk, I., Graber, E. R., Anttila, T., Mentel, T. F., and Rudich, Y.: Hygroscopic growth of atmospheric and model humic-like substances, J. Geophys. Res.-Atmos., 112, 13, doi:D0521110.1029/2006jd0074-42, 2007.

Duarte, R., Pio, C. A., and Duarte, A. C.: Spectroscopic study of the water-soluble organic matter isolated from atmospheric aerosols collected under different atmospheric conditions, Analytica Chimica Acta, 530, 7-14, doi:10.1016/j.aca.2004.08.049, 2005.

Facchini, M. C., Fuzzi, S., Zappoli, S., Andracchio, A., Gelencser, A., Kiss, G., Krivacsy, Z., Meszaros, E., Hansson, H. C., Alsberg, T., and Zebuhr, Y.: Partitioning of the organic aerosol component between fog droplets and interstitial air, J. Geophys. Res.Atmos., 104, 26821-26832, doi:10.1029/1999jd900349, 1999.

Frosch, M., Prisle, N. L., Bilde, M., Varga, Z., and Kiss, G.: Joint effect of organic acids and inorganic salts on cloud droplet activation, Atmos. Chem. Phys., 11, 3895-3911, doi:10.5194/acp11-3895-2011, 2011. 
Fuzzi, S., Decesari, S, Facchini, M. C., Matta, E., Mircea, M., and Tagliavini E.: A simplified model of the water soluble organic component of atmospheric aerosols, Geophys. Res. Lett., 28, doi:10.1029/2001g1013418, 2001.

Gelencser, A., Meszaros, T., Blazso, M., Kiss, G., Krivacsy, Z., Molnar, A., and Meszaros, E.: Structural characterisation of organic matter in fine tropospheric aerosol by pyrolysis-gas chromatography-mass spectrometry, J. Atmos. Chem., 37, 173183, doi:10.1023/a:1006402731340, 2000.

Gerber, H. E., Hoppel, W. A., and Wojciechowski, T. A.: experimental-verification of theoretical relationship between size and critical supersaturation of salt nuclei, J. Atmos. Sci., 34, 1836-1841, doi:10.1175/15200469(1977)034<1836:evottr>2.0.co;2, 1977.

Gysel, M., Weingartner, E., Nyeki, S., Paulsen, D., Baltensperger, U., Galambos, I., and Kiss, G.: Hygroscopic properties of watersoluble matter and humic-like organics in atmospheric fine aerosol, Atmos. Chem. Phys., 4, 35-50, doi:10.5194/acp-4-352004, 2004.

Hallquist, M., Wenger, J. C., Baltensperger, U., Rudich, Y., Simpson, D., Claeys, M., Dommen, J., Donahue, N. M., George, C., Goldstein, A. H., Hamilton, J. F., Herrmann, H., Hoffmann, T., Iinuma, Y., Jang, M., Jenkin, M. E., Jimenez, J. L., Kiendler-Scharr, A., Maenhaut, W., McFiggans, G., Mentel, Th. F., Monod, A., Prévôt, A. S. H., Seinfeld, J. H., Surratt, J. D., Szmigielski, R., and Wildt, J.: The formation, properties and impact of secondary organic aerosol: current and emerging issues, Atmos. Chem. Phys., 9, 5155-5236, doi:10.5194/acp-9-51552009, 2009.

Hämeri, K., Charlson, R., and Hansson, H. C.: Hygroscopic properties of mixed ammonium sulfate and carboxylic acids particles, AIChE Journal, 48, 1309-1316, doi:10.1002/aic.690480617, 2002.

Havers, N., Burba, P., Lambert, J., and Klockow, D.: Spectroscopic characterization of humic-like substances in airborne particulate matter, J. Atmos. Chem., 29, 45-54, doi:10.1023/a:1005875225800, 1998.

Hegde, P. and Kawamura, K.: Seasonal variations of water-soluble organic carbon, dicarboxylic acids, ketocarboxylic acids, and $\alpha$ dicarbonyls in Central Himalayan aerosols, Atmos. Chem. Phys., 12, 6645-6665, doi:10.5194/acp-12-6645-2012, 2012.

Intergovernmental Panel on Climate Change (IPCC): Climate Change 2007: The Physical Science Basis: Working Group I Contribution to the Fourth Assessment Report of the IPCC, edited by: Solomon, S., Qin, D., Manning, M., Chen, Z., Marquis, M., Averyt, K. B, Tignor M., and Mille H. L., Cambridge Univ. Press, New York, 2007.

Jimenez, J. L., Canagaratna, M. R., Donahue, N. M., Prevot, A. S. H., Zhang, Q., Kroll, J. H., DeCarlo, P. F., Allan, J. D., Coe, H., Ng, N. L., Aiken, A. C., Docherty, K. S., Ulbrich, I. M., Grieshop, A. P., Robinson, A. L., Duplissy, J., Smith, J. D., Wilson, K. R., Lanz, V. A., Hueglin, C., Sun, Y. L., Tian, J., Laaksonen, A., Raatikainen, T., Rautiainen, J., Vaattovaara, P., Ehn, M., Kulmala, M., Tomlinson, J. M., Collins, D. R., Cubison, M. J., Dunlea, E. J., Huffman, J. A., Onasch, T. B., Alfarra, M. R., Williams, P. I., Bower, K., Kondo, Y., Schneider, J., Drewnick, F., Borrmann, S., Weimer, S., Demerjian, K., Salcedo, D., Cottrell, L., Griffin, R., Takami, A., Miyoshi, T., Hatakeyama, S., Shimono, A., Sun, J. Y., Zhang, Y. M., Dzepina,
K., Kimmel, J. R., Sueper, D., Jayne, J. T., Herndon, S. C., Trimborn, A. M., Williams, L. R., Wood, E. C., Middlebrook, A. M., Kolb, C. E., Baltensperger, U., and Worsnop, D. R.: Evolution of organic aerosols in the atmosphere, Science, 326, 1525-1529, doi:10.1126/science.1180353, 2009.

Jung, J., Tsatsral, B., Kim, Y. J., and Kawamura, K.: Organic and inorganic aerosol compositions in Ulaanbaatar, Mongolia, during the cold winter of 2007 to 2008: Dicarboxylic acids, ketocarboxylic acids, and alpha-dicarbonyls, J. Geophys. Res.-Atmos., 115, D22, doi:10.1029/2010jd014339, 2010.

Kanakidou, M., Seinfeld, J. H., Pandis, S. N., Barnes, I., Dentener, F. J., Facchini, M. C., Van Dingenen, R., Ervens, B., Nenes, A., Nielsen, C. J., Swietlicki, E., Putaud, J. P., Balkanski, Y., Fuzzi, S., Horth, J., Moortgat, G. K., Winterhalter, R., Myhre, C. E. L., Tsigaridis, K., Vignati, E., Stephanou, E. G., and Wilson, J.: Organic aerosol and global climate modelling: a review, Atmos. Chem. Phys., 5, 1053-1123, doi:10.5194/acp-5-1053-2005, 2005.

Kawamura, K., Steinberg, S., Ng, L., and Kaplan, I. R.: Wet deposition of low molecular weight mono- and di-carboxylic acids, aldehydes and inorganic species in Los Angeles, Atmos. Environ., 35, 3917-3926, doi:10.1016/s1352-2310(01)00207-2, 2001a.

Kawamura, K., Yokoyama, K., Fujii, Y., and Watanabe, O.: A Greenland ice core record of low molecular weight dicarboxylic acids, ketocarboxylic acids, and alpha-dicarbonyls: A trend from Little Ice Age to the present (1540-1989 AD), J. Geophys. Res.Atmos., 106, 1331-1345, doi:10.1029/2000jd900465, 2001b.

Kerminen, V. M., Ojanen, C., Pakkanen, T., Hillamo, R., Aurela, M., and Merilainen, J.: Low-molecular-weight dicarboxylic acids in an urban and rural atmosphere, J. Aerosol Sci., 31, 349-362, doi:10.1016/s0021-8502(99)00063-4, 2000.

Krivacsy, Z., Kiss, G., Varga, B., Galambos, I., Sarvari, Z., Gelencser, A., Molnar, A., Fuzzi, S., Facchini, M. C., Zappoli, S., Andracchio, A., Alsberg, T., Hansson, H. C., and Persson, L.: Study of humic-like substances in fog and interstitial aerosol by size-exclusion chromatography and capillary electrophoresis, Atmos. Environ., 34, 4273-4281, doi:10.1016/s13522310(00)00211-9, 2000.

Lightstone, J. M., Onasch, T. B., Imre, D., and Oatis, S.: Deliquescence, efflorescence, and water activity in ammonium nitrate and mixed ammonium nitrate/succinic acid microparticles, J. Phys. Chem. A, 104, 9337-9346, doi:10.1021/jp002137h, 2000.

Low, R. D. H.: A comprehensive report on nineteen condensation nuclei. I. equilibrium growth and physical properties, White Sands Missile Range, NM, USA, 551 pp., 1969.

Mader, B. T., Yu, J. Z., Xu, J. H., Li, Q. F., Wu, W. S., Flagan, R. C., and Seinfeld, J. H.: Molecular composition of the water-soluble fraction of atmospheric carbonaceous aerosols collected during ACE-Asia, J. Geophys. Rese.-Atmos., 109, D6, doi:10.1029/2003jd004105, 2004.

Marcolli, C., Luo, B., and Peter, T.: Mixing of the organic aerosol fractions: liquids as the thermodynamically stable phases, J. Phys. Chem., 108, 2216-2224, 2004.

Mayol-Bracero, O. L., Guyon, P., Graham, B., Roberts, G., Andreae, M. O., Decesari, S., Facchini, M. C., Fuzzi, S., and Artaxo, P.: Water-soluble organic compounds in biomass burning aerosols over Amazonia - 2. Apportionment of the chemical composition and importance of the polyacidic frac- 
tion, J. Geophys. Res.-Atmos., 107, LBA 59-1-LBA 59-15 , doi:10.1029/2001jd000522, 2002.

Meyer, N. K., Duplissy, J., Gysel, M., Metzger, A., Dommen, J., Weingartner, E., Alfarra, M. R., Prevot, A. S. H., Fletcher, C., Good, N., McFiggans, G., Jonsson, Å. M., Hallquist, M., Baltensperger, U., and Ristovski, Z. D.: Analysis of the hygroscopic and volatile properties of ammonium sulphate seeded and unseeded SOA particles, Atmos. Chem. Phys., 9, 721-732, doi:10.5194/acp-9-721-2009, 2009.

Mochida, M. and Kawamura, K.: Hygroscopic properties of levoglucosan and related organic compounds characteristic to biomass burning aerosol particles, J. Geophys. Res.-Atmos., 109, D21, doi:10.1029/2004jd004962, 2004.

Moore, R. H. and Raymond, T. M.: HTDMA analysis of multicomponent dicarboxylic acid aerosols with comparison to UNIFAC and ZSR, J. Geophys. Res.-Atmos., 113, D4, doi:10.1029/2007jd008660, 2008.

Mukai, H. and Ambe, Y.: Characterization of a humic acidlike brown substance in airborne particulate matter and tentative identification of its origin, Atmos. Environ., 20, 813-819, doi:10.1016/0004-6981(86)90265-9, 1986.

Narukawa, M., Kawamura, K., Li, S. M., and Bottenheim, J. W.: Dicarboxylic acids in the Arctic aerosols and snowpacks collected during ALERT 2000, Atmos. Environ., 36, 2491-2499, doi:10.1016/s1352-2310(02)00126-7, 2002.

Pandis, S. N., Wexler, A. S., and Seinfeld, J. H.: Dynamics of tropospheric aerosols, J. Phys. Chem., 99, 9646-9659, doi:10.1021/j100024a003, 1995.

Peng, C., Chan, M., and Chan, C.: The hygroscopic properties of dicarboxylic and multifunctional acids: measurements and UNIFAC predictions, Environ. Sci. Technol., 35, 4495-4501, doi:10.1021/es0107531, 2001.

Pöschl, U.: Atmospheric aerosols: Composition, transformation, climate and health effects, Angewandte Chemie-International Edition, 44, 7520-7541, doi:10.1002/anie.200501122, 2005.

Prenni, A.: Water uptake of internally mixed particles containing ammonium sulfate and dicarboxylic acids, Atmos. Environ., 37, 4243-4251, doi:10.1016/s1352-2310(03)00559-4, 2003.

Pruppacher, H. R. and Klett, J. D.: Microphysics of Clouds and Precipitation, 2nd Ed., Springer Publications, New York, USA 1997.

Putaud, J. P., Raes, F., Van Dingenen, R., Bruggemann, E., Facchini, M. C., Decesari, S., Fuzzi, S., Gehrig, R., Huglin, C., Laj, P., Lorbeer, G., Maenhaut, W., Mihalopoulos, N., Mulller, K., Querol, X., Rodriguez, S., Schneider, J., Spindler, G., ten Brink, H., Torseth, K., and Wiedensohler, A.: European aerosol phenomenology-2: chemical characteristics of particulate matter at kerbside, urban, rural and background sites in Europe, Atmos. Environ., 38, 2579-2595, doi:10.1016/j.atmosenv.2004.01.041, 2004.

Roberts, G. C., Andreae, M. O., Maenhaut, W., and FernandezJimenez, M. T.: Composition and sources of aerosol in a central African rain forest during the dry season, J. Geophys. Res.Atmos., 106, 14423-14434, doi:10.1029/2000jd900774, 2001.

Rogers, R. R. and Yau, M. K.: A short course in cloud physics, 3rd Edn., Butterworth-Heinemann Publications, Massachusetts, USA, 1989.

Rogge, W. F., Mazurek, M. A., Hildemann, L. M., Cass, G. R., and Simoneit, B. R. T.: Quantification of urban organic aerosols at a molecular-level - identification, abundance and seasonal-variation, Atmos. Environ. Pt. A, 27, 1309-1330, doi:10.1016/0960-1686(93)90257-y, 1993.

Saxena, P. and Hildemann, L. M.: Water-soluble organics in atmospheric particles: A critical review of the literature and application, J. Atmos. Chem., 24, 57-109, doi:10.1029/2003jd003775, 1996.

Simoneit, B. R. T., Schauer, J. J., Nolte, C. G., Oros, D. R., Elias, V. O., Fraser, M. P., Rogge, W. F., and Cass, G. R.: Levoglucosan, a tracer for cellulose in biomass burning and atmospheric particles, Atmos. Environ., 33, 173-182, doi:10.1016/s13522310(98)00145-9, 1999.

Sjogren, S., Gysel, M., Weingartner, E., Baltensperger, U., Cubison, M. J., Coe, H., Zardini, A. A., Marcolli, C., Krieger, U. K., and Peter, T.: Hygroscopic growth and water uptake kinetics of two-phase aerosol particles consisting of ammonium sulfate, adipic and humic acid mixtures, J. Aerosol Sci., 38, 157-171, doi:10.1016/j.jaerosci.2006.11.005, 2007.

Sloane, C. S. and Wolff, G. T.: Prediction of ambient light-scattering using a physical model responsive to relative-humidity - validation with measurements from Detroit, Atmos. Environ., 19, 669680, doi:10.1016/0004-6981(85)90046-0, 1985.

Stokes, R. H. and Robinson, R. A.: Interactions in aqueous nonelectrolyte solutions, I. solute-solvent equilibria, J. Phys. Chem., 70, 2126-2131, doi:10.1021/j100879a010, 1966.

Svenningsson, B., Rissler, J., Swietlicki, E., Mircea, M., Bilde, M., Facchini, M. C., Decesari, S., Fuzzi, S., Zhou, J., Mønster, J., and Rosenørn, T.: Hygroscopic growth and critical supersaturations for mixed aerosol particles of inorganic and organic compounds of atmospheric relevance, Atmos. Chem. Phys., 6, 1937-1952, doi:10.5194/acp-6-1937-2006, 2006.

Talbot, R. W., Andreae, M. O., Andreae, T. W., and Harriss, R. C.: Regional aerosol chemistry of the Amazon basin during the dry season, J. Geophys. Res.-Atmos., 93, 1499-1508, doi:10.1029/JD093iD02p01499, 1988.

Talbot, R. W., Andreae, M. O., Berresheim, H., Artaxo, P., Garstang, M., Harriss, R. C., Beecher, K. M., and Li, S. M.: Aerosol chemistry during the wet season in central Amazonia - the influence of long-range transport, J. Geophys. Res.-Atmos., 95, 1695516969, doi:10.1029/JD095iD10p16955, 1990.

Tang, I. N. and Munkelwitz, H. R.: Composition and temperaturedependence of the deliquescence properties of hygroscopic aerosols, Atmos. Environ. Pt. A, 27, 467-473, doi:10.1016/09601686(93)90204-c, 1993.

Wise, M., Surratt, J. D., Curtis, D. B., Shilling, J. E., and Tolbert, M. A.: Hygroscopic growth of ammonium sulfate/dicarboxylic acids, J. Geophys. Res., 108, D20, doi:10.1029/2003jd003775, 2003.

Wu, Z. J., Nowak, A., Poulain, L., Herrmann, H., and Wiedensohler, A.: Hygroscopic behavior of atmospherically relevant water-soluble carboxylic salts and their influence on the water uptake of ammonium sulfate, Atmos. Chem. Phys., 11, 1261712626, doi:10.5194/acp-11-12617-2011, 2011.

Zamora, I. R., Tabazadeh, A., Golden, D. M., and Jacobson, M. Z.: Hygroscopic growth of common organic aerosol solutes, including humic substances, as derived from water activity measurements, J. Geophys. Res.-Atmos., 116, D23, doi:10.1029/2011jd016067, 2011.

Zappoli, S., Andracchio, A., Fuzzi, S., Facchini, M. C., Gelencser, A., Kiss, G., Krivacsy, Z., Molnar, A., Meszaros, E., Hansson, H. 
C., Rosman, K., and Zebuhr, Y.: Inorganic, organic and macromolecular components of fine aerosol in different areas of Europe in relation to their water solubility, Atmos. Environ., 33, 27332743, doi:10.1016/s1352-2310(98)00362-8, 1999.
Zhang, Y. -C., Rossow, W. B., Stackhouse, P. W., Romanou, A., and Wielicki, B. A.: Decadal variations of global energy and ocean heat budget and meridional energy transports inferred from recent global data sets, J. Geophys. Res.-Atmos., 112, D22, doi:10.1029/2007JD008435, 2007. 